\title{
A survey of GNSS-based Research and Developments for the European railway signaling
}

\author{
Juliette Marais, Julie Beugin, Marion Berbineau, Member, IEEE
}

\begin{abstract}
Railways have already introduced satellite-based localization systems for non-safety related applications. Driven by economic reasons, the use of these systems for new services and, in particular, their introduction in signaling system is seriously investigated today and tested all around the world. Because of the weight of their history, their strong normative context and the high requested level of safety, the introduction is relatively slow. The aim of this paper is to provide a survey of past and current programs dealing with GNSS (Global Navigation Satellite Systems) as a basis to introduce main issues relative to context, standards, performance requirements and safety proofs. Links with aeronautical concepts are also presented, illustrating the transposable principles and the limits due to the land transport environment.
\end{abstract}

Index Terms - Localization, Railway safety, Rail Transportation, Satellite navigation systems, Signaling

\section{INTRODUCTION}

$I^{2}$ is today well known that Intelligent Transport Systems strongly rely on location information. When thinking about ITS, one thinks first about road transport. However, the location of a train is also a key data in railway intelligent systems. Train locations are used not only for fleet dispatcher information, for passenger information, dangerous good tracking [1], but also for accurate locations such as selective door opening [2] or maintenance [3]. Depending on the service required, the object to be located can be a locomotive, a wagon, or even a worker-on-track to prevent him from accidents.

Train location is also of main use in signaling applications. In Europe, the train position is processed with the help of equipment on tracks. The typical equipment is a track circuit, i.e. a simple electrical device used to detect the presence or absence of a train on rail tracks. This equipment is thus not devoted to locating the train specifically but to locating it indirectly on a track portion. The location is also known with the help of the detectors placed along the track, on which relies the train protection. These sensors can be transponders, which communicate with the train on-board equipment when the train runs over it. Due to historical deployment of railways, different versions of sensors exist and can be

This paragraph of the first footnote will contain the date on which you submitted your paper for review.

J. Marais, J. Beugin and M. Berbineau, are with the French institute of science and technology for transport, development and networks, Villeneuve d’Ascq, 59650 France. (e-mail: surname.name@ifsttar.fr). encountered on the European network [4]. In order to replace all these incompatible safety systems by an interoperable common solution, Europe has developed the European Train Control System (ETCS) for the signaling, control and train protection. The ETCS is composed of four levels to smooth the system progress from the actual system to a lighter system capable of operating with a minimum of equipment on tracks. In ETCS, a balise or a group of balises is installed on tracks to detect when the train is passing over it/them and thus to detect the presence of a train on the track section [5]. The balise initializes the odometer, and the train position is computed by the odometer as a distance run since the balise detection.

For non-safety related functions such as information services or asset location and monitoring, GNSS (Global Navigation Satellite Systems) technology offers today low-cost and effective solutions [6]. The users' positioning information can be communicated, when available, to a central server via a classical communication device without the need to ensure integrity, safety or robustness. For maintenance, track surveying or for locating signaling assets, ARTC (Australian Rail Track Corporation) in Australia [7] uses augmented GNSS that offers satisfying services for them. Other considered applications are dedicated to fuel economy software to calculate optimal driving profile.

This paper intends to address the state of the art of GNSS uses or experiences in railway applications for safety-critical applications and in particular for signaling systems. The first section will remind the basics of GNSS-based localization and the context of signaling in Europe and elsewhere for a good understanding of the following issues. The rest of the paper will focus successively on each issue to be addressed for the introduction of GNSS in the railway:

- Required positioning performances will need to be defined since no equivalent values are today defined in the railway standards. The discussion will focus on their qualification and their quantification.

- The solutions developed or to be developed will be presented, that aim to answer to the previously defined requirements.

- In order to assess their introduction in signaling systems, the developed solutions have to be evaluated. Several challenges have to be faced: their evaluation in real operational conditions and the safety proof.

These issues still require to be completely solved to convince users of deploying GNSS, to provide a certified solution and to definitely penetrate the railway networks. 


\section{BASICS ON GNSS}

Satellite-based positioning methods rely on propagation time measurement. Position is derived by triangulation as illustrated in figure 1. The best known Global Navigation Satellite Systems (GNSS) is today the American Global Position System (GPS). But a Russian constellation does also exist, GLONASS, as well as half of a European one, GALILEO (18 satellites in orbit in December 2016) and partially also a Chinese one, BEIDOU (20 satellites in orbit in June 2016). All of these systems are composed of nongeostationary satellites.

The basic principles of these GNSS are the same. Each of the satellites broadcasts a continuous coded signal. The code is different for every satellite so the receiver is able to separate one message from another and to identify the transmitter identity. A GNSS chipset receives and processes simultaneously all of the signals reaching its antenna and estimates the time of arrival (TOA) of each of these signals. These times multiplied by the speed of the signal (i.e., the speed of light for GNSS) will represent the emitter-to-receiver distances, called pseudo-ranges. The reception of $n$ (at least four) satellites will allow the receiver to benefit of $n$ observations to solve the system of $n$ equations where the unknowns are $(x, y, z, \delta t) ;(x, y, z)$ being the antenna position and $\delta t$ the clock bias coming from the user and satellite clocks offsets. The system resolution is classically performed with a least square estimator or a Kalman Filter.

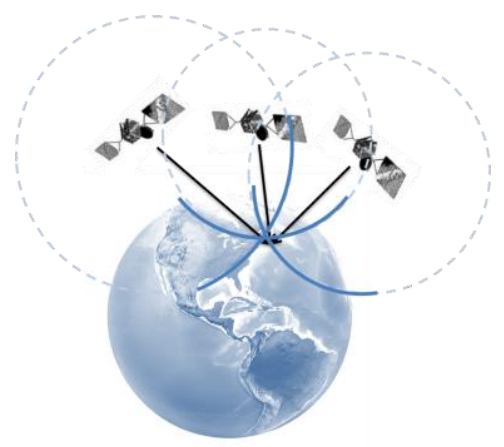

Fig. 1. GNSS-based triangulation. For each satellite, a pseudorange is estimated that enable the receiver to place the user on a sphere, centered on the satellite emitting. The intersection of three spheres at least allows the receiver to compute its position.

GNSS positioning performances are strongly related to measurement accuracy, as well as the satellite distribution around the reception antenna. Indeed, the straighter the path of the signal between the sender and the receiver is, the more accurate will be the satellite-receiver distance estimation.

\section{GNSS-BASED SOLUTIONS FOR SIGNALING APPLICATIONS}

\section{A. The European context}

Historically, in Europe, each country developed its own railway infrastructure, equipment and operational rules. The consequences are heterogeneity of electrification, rolling stock, maintenance and exploitation rules, signaling... Now that the trains cross frontiers, traveling for example from Paris to Amsterdam via Belgium, Europe is deploying the European Rail Traffic Management System (ERTMS) to harmonize rules and regulations. ETCS is the ERTMS sub-system dedicated to control and to protect trains. The main components are the radio system (GSM-R - GSM for Railway) and the balise system (Eurobalise). Migration is progressive and performed by stages from level 0 to 3 . The goal is first to let coexist current external systems and new balises and to progressively move some of the trackside equipment to transpose intelligence on-board (level 3).

In current railway systems, a basis for safety is the division of the tracks into fixed blocks managed by line side signals allowing the train to enter in a block or not. Block entrance is detected with the help of track circuits or balises in ERTMS. Movement Authorization is given depending on the presence or not of a train in the blocks ahead. The odometry on-board sub-system positions the train relatively to the last encountered balise.

In levels 1 and 2 of ETCS, the knowledge of the train position is based on information given by an odometer and a beacon reader, interfaced with the EVC (European Vital Computer) train-borne sub-system (cf. figure 2). Such sensors are well known and well controlled by the railway community, which has a certain confidence in them. However, the global ETCS infrastructure is costly and this cost slows down its deployment. Furthermore, the decrease of costs is needed to renew regional and conventional lines in order to shift mobility from road to rail. It is then necessary for future systems to think about alternative solutions [8].

GNSS is considered in the highest level of ETCS or its declination to regional lines, namely ETCS L3 and ETCS Regional.
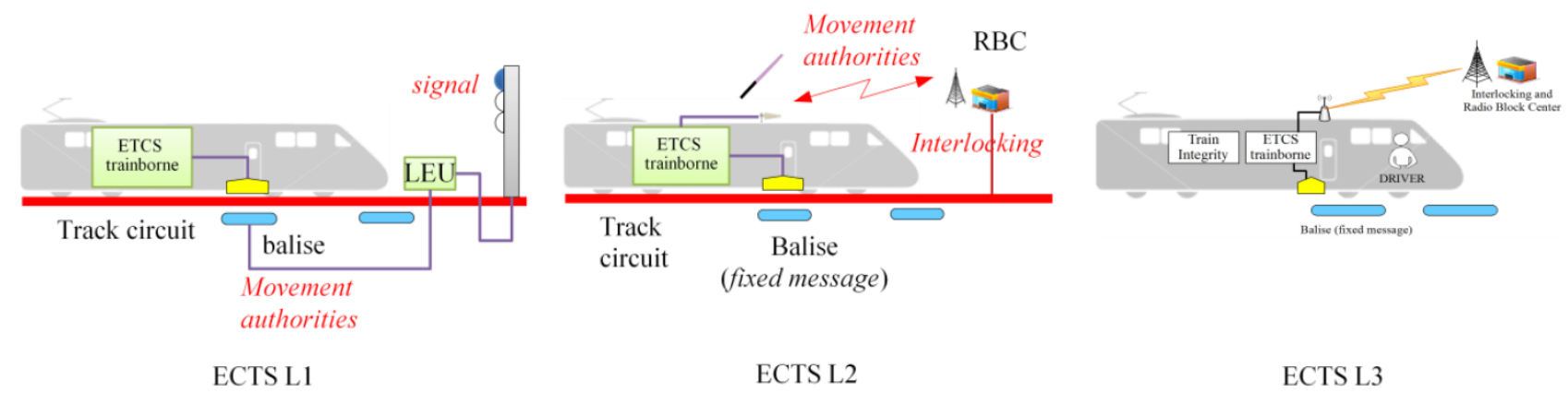

Fig. 2. ETCS Levels [86]. 
In level 3, no line side signals will be required for delivering movement authorities. A train shall be able to locate itself [9]. All information will be exchanged between the ETCS onboard system and the RBC trackside system (Radio Block Center) through mobile networks. Two data are communicated by the train to the RBC: its location and the confirmation that the train did not lose any wagon. This information is called "integrity" in the railway domain and is an element of the safety. This last level of ETCS shall also improve line capacity by making it possible to manage circulations with moving blocks. In this context, GNSS is investigated to be the basis for new embedded train locator.

The use of GNSS for low cost signaling solution and, in particular, in the highest level of ETCS (level 3) and the ERTMS Regional, is an issue since the beginning of the 2000's [10]. With several projects, the European Commission, through the successive Framework Programs, funded researches in order to explore and promote the use of satellites for such solutions. First main projects were APOLO [11], GADEROS [12] and LOCOPROL [13] but one can mention tens of others in the past decade until the recent GaLoROI [14] or 3inSat [15] projects. All these projects, if they did not lead to operational commercialized products, surely helped GNSS to be introduced in railway mentalities. The concept of "virtual balises" also emerged to allow this new technology to penetrate the railway operational modes. The virtual balises are virtual points, recorded in an embedded geographic database. These points can be the coordinates of the real (removed) physical balises. The goal of the virtual balise concept is to detect the position of the train when passing over the identified points by comparing the GNSS-based location of the train with the database. The train delivers then the same telegram that would have been sent with the use of the physical balise. As such, the process could be as transparent as possible for the global system. The virtual balise has been investigated in lots of projects since the beginning of the studies such as in RUNE [16] or recently in 3InSat or ERSAT [17].

One line that embeds a light GNSS solution is today operated in Europe: a single line of $100 \mathrm{~km}$ long with a system developed by the University of Applied Sciences Upper Austria and operated by Stern \& Hafferl. An on-board unit communicates the train position to the trackside train controller which is responsible for the movement authority of the train [2].

In April 2012, a big recognition step has occurred when the European Commission, the European Railway Agency and the European Rail Sector Associations signed together an ERTMS Memorandum of Understanding concerning the strengthening of cooperation for the management of ERTMS. It mentions in particular that GNSS can play a major role in the rail sector [18].

In the same period, new initiatives have been launched such as the NGTC project (Next Generation Train Control) that aims to study how the new developments for ERTMS/ETCS (for interoperable networks) and those for CBTC (Communication-Based Train Control) systems (for urban networks) can be mutualized. Satellite positioning is one of the NGTC focuses. Finally, the European Shift2Rail program in its $2^{\text {nd }}$ innovative program (IP2) on signaling especially focuses on fail-safe train positioning for advanced traffic management and control systems.

\section{B. Other initiatives}

In 2008, the US congress enacted the Rail Safety Improvement Act to improve railroad safety. The most significant change was the mandate requiring Positive Train Control (PTC) technology to be installed on most of the US railroad network by 2015 [19]. Train location is a basic function of PTC combined with wireless data link [20] and is GPS-based. Its basic principle is drawn on figure 3. GPS is intended to mitigate the significant cost of deployment of intrack transponders (balises) on railroads nationwide (Joint Council on Transit Wireless Communications 2012). The solution can be enhanced by track beacons or differential GPS stations hybridized with wheel sensors but [21] demonstrates the capability of low-cost on-board components to discriminate cross-track with data fusion without any trackside infrastructure. "To deploy the Nationwide Differential Global Positioning System (NDGPS) as a nationwide, uniform, and continuous positioning system, suitable for train control" is a goal for the federal Railroad Administration even if the dead line has been delayed this year. One can also mention the HRI-2000 system developed by the Minnesota Department of Transportation for a low-cost active level crossing warning system [22].

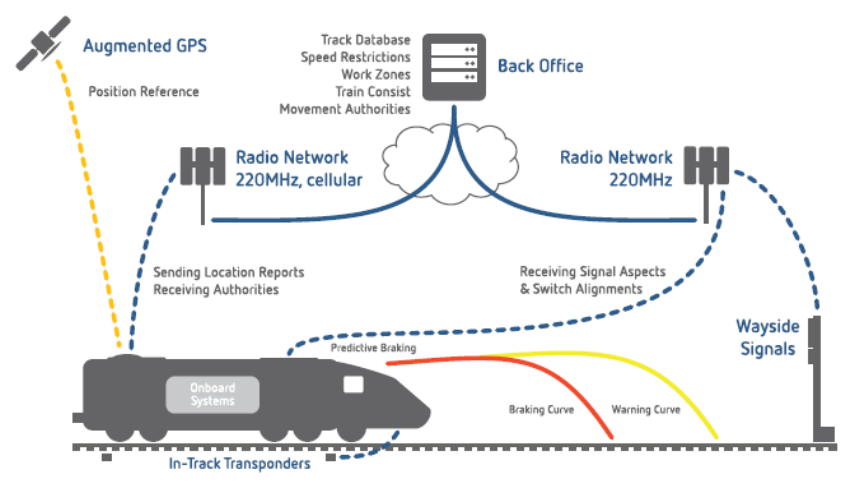

Fig. 3. PTC operation [19].

In Australia, ARTC is an infrastructure manager that invests into the development of the Automated Train Management System (ATMS) based on GNSS and inertial monitoring systems. This system aims to identify the front and back of the trains within 2 meters accuracy. The information is then communicated to a central train control system. The goal of the ATMS is to replace trackside signaling equipment by incab displays of movement authorities to the driver with a high reliability and safety integrity. The concept is under experimental evaluation. The study published in [7] announces the ATMS introduction on the ARTC network by 2020.

The ITARUS-ATC (ITAlian-RUSsian - Automatic Train Control) system developed for Russia, in order to modernize train control, signaling, automation, and transport safety systems, includes the application of GLONASS/GPS satellite 


\section{> REPLACE THIS LINE WITH YOUR PAPER IDENTIFICATION NUMBER (DOUBLE-CLICK HERE TO EDIT) <}

navigation technology. Deployment of the Sotchi pilot line is finished since 2015 .

China modern lines rely on a CBTC (Communication-Based Train Control) system. The CTCS (Chinese Train Control System) is different from the ERTMS described in the previous section, but with similar features. The highest level of deployment will allow the system to protect circulations with moving blocks and positions provided either by GPS or balises [23].

Let's finish this presentation of the initiatives by mentioning specific focuses on GNSS-based solutions for train integrity in ERTMS L3 [9], for energy optimized driving style management [24] or for Train Collision Avoidance Systems [25][26][27] that will not be specifically detailed in this survey. Parallel track discrimination will not be targeted in this survey either as it requires very accurate lateral accuracy and a very safe information.

\section{REQUIRED POSITIONING PERFORMANCES}

Aeronautics defines required positioning performances (RNP) according to ICAO (International Civil Aviation Organization) standards. Operations are divided into en-route, approach, landing and departure and are commonly accepted by the aeronautical stakeholders. Railway approaches differ from the aviation ones for organizational as well as technical reasons.

A. How to qualify required GNSS performances in the railway domain?

Inside the GNSS community, system performances are qualified by four criteria: availability, continuity, accuracy and integrity. These performances, mainly driven by aeronautics and specified by the ICAO, do not have direct correspondence to railway requirement criteria, usually qualified in terms of reliability, availability, maintainability and safety (RAMS) as represented by [28] on figure 4. A particular example concerns the "integrity" word. For the navigation users, the "integrity" is a quantitative measure characterizing the confidence in the position provided. In railways, users talk about "safety integrity" to encompass a larger number of requirements over the lifecycle of a safety system. "Integrity" employed alone refers to the integrity of the train, that is to say, the fact that the train did not lose any wagon.

GNSS positioning introduces an issue of performances not questioned until today. Indeed, balises are fixed on track with an accurate location. The use of GNSS, i.e. the use of an embedded wireless system, introduces a question about system accuracy or availability that does not exist with physical balises. Moreover, railway operational rules, regulations and standards are not structured in terms of operations as do the aeronautical users.

Accuracy requirements will vary depending on the use of the position information. As an example, [29] illustrates the question of "stop points" at switches as represented in figure 5. In such a point, the position of the train waiting for free way just before a track junction may be accurate and reliable enough so that the train "incoming on-the-other track" will not hurt it.

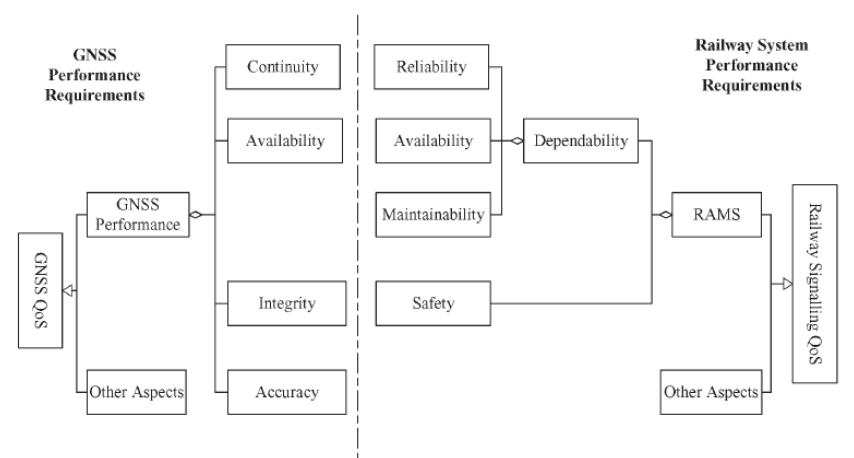

Fig. 4. GNSS and railway performance requirements comparison [28].

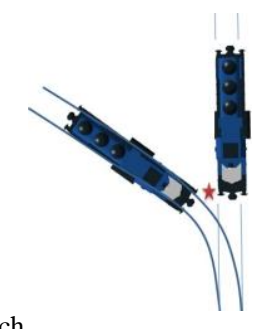

Fig. 5. Stop-point at a switch.

In other projects, the objective is to substitute physical balises with GNSS-based virtual balises. To act like a physical balise, the system shall detect when the train reaches a virtual balise previously identified and recorded in a Virtual Balise map database. Figure 6 represents a classical block secured by a track circuit that will detect the presence of a train (or not) between $\mathrm{A}$ and $\mathrm{B}$. Before migrating towards virtual balises, the system shall guarantee that the train ahead passes (entirely) the virtual balise [30] in order to guarantee that the track between $\mathrm{A}$ and $\mathrm{B}$ is free before delivering a movement authority to the waiting train. Then, requirements have to specify how accurate the position of the train compared to the virtual balise has to be and in particular the position of the train tail. In the RUNE project, the long term objective is even to allow operation with moving blocks. The performance objectives summarized in table I have been defined by the consortium in order to provide a protected distance of $50 \mathrm{~m}$ and to raise timely alerts (for the integrity of the localization) when this cannot be guaranteed [31].

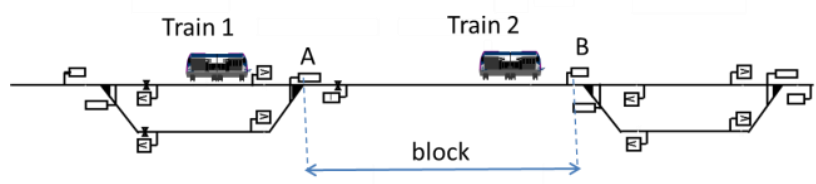

Fig. 6. Train protection with fixed blocks.

TABLE I. RUNE OBJECTIVES FOR VIRTUAL BALISE REQUIREMENTS [31]

\begin{tabular}{lll}
\hline & \multicolumn{1}{c}{ ERTMS } & \multicolumn{1}{c}{ RUNE objectives } \\
\hline Position Accuracy & $5 \mathrm{~m}+5 \%$ of travelled space & $3 \mathrm{~m}, 95 \%$ (GNSS + WAAS/EGNOS) \\
Velocity Accuracy & $2 \mathrm{~km} / \mathrm{h} \mathrm{v}<30 \mathrm{~km} / \mathrm{h}$ & $2 \mathrm{~km} / \mathrm{h} 95 \%$ (GNSS + WAAS/EGNOS) \\
& $12 \mathrm{~km} / \mathrm{h} \mathrm{v}<500 \mathrm{~km} / \mathrm{h}$ & $>99.9 \%$. for a $50 \mathrm{~m}$ Protected distance \\
Position Confidence & $>99.9 \%$. & better than $99 \%$ \\
Availability & better than $99 \%$ & (Level 3 applications) \\
Time to Alert & $<5 \mathrm{~s}$ & better than $5 \mathrm{sec}$ (Safety Level 3 applications) \\
\hline
\end{tabular}

The table here reported summarizes ERTMS main requirements and RUNE objectives. 
TABLE II

REQUIREMENT TABLE PUBLISHED BY THE GNSS RAIL USER FORUM [32]

\begin{tabular}{|c|c|c|c|c|c|c|c|c|c|}
\hline \multirow[t]{3}{*}{ No } & \multirow[t]{3}{*}{ Application } & \multicolumn{8}{|c|}{ Requirement } \\
\hline & & \multirow{2}{*}{$\begin{array}{c}\text { Accuracy } \\
\text { Horizontal (m) }\end{array}$} & \multicolumn{2}{|c|}{ Integrity } & \multirow{2}{*}{$\begin{array}{l}\text { Availability } \\
\begin{array}{c}\% \text { of mission } \\
\text { time }\end{array}\end{array}$} & \multirow{2}{*}{$\begin{array}{c}\text { Service } \\
\text { interrupt } \\
\text { threshold } \\
\text { (seconds) }\end{array}$} & \multirow[t]{2}{*}{ Continuity } & \multirow[t]{2}{*}{ Coverage } & \multirow{2}{*}{$\begin{array}{r}\text { Fix rate } \\
\text { (seconds) }\end{array}$} \\
\hline & & & Alert limit (m) & $\begin{array}{c}\text { Maximum } \\
\text { time to } \\
\text { alarm (s) }\end{array}$ & & & & & \\
\hline \multicolumn{10}{|c|}{ Safety related applications } \\
\hline 1 & $\begin{array}{l}\text { ex: ATC on high density } \\
\text { lines / Station / Parallel track }\end{array}$ & (1) & 2.5 & $<1.0$ & $>99.98$ & $<5$ & $>99.98$ & ELM & 1 \\
\hline II & $\begin{array}{l}\text { ex: Train Control on medium } \\
\text { density lines }\end{array}$ & $(10)$ & 20 & $<1.0$ & $>99.98$ & $<5$ & $>99.98$ & ELM & 1 \\
\hline III & $\begin{array}{l}\text { ex: Train Control on low } \\
\text { density lines }\end{array}$ & (25) & 50 & $<1.0$ & $>99.98$ & $<5$ & $>99.98$ & ELM & $T B D$ \\
\hline \multicolumn{10}{|c|}{ Mass commercial / information and management - operational applications } \\
\hline IV & $\begin{array}{l}\text { Tracing \& Tracking of } \\
\text { vehicles }\end{array}$ & 50 & 125 & $<10$ & 99,9 & TBD & TBD & ELM & TBD \\
\hline $\mathrm{v}$ & Cargo monitoring & 100 & 250 & $<30$ & 99.5 & TBD & TBD & ELM & TBD \\
\hline VI & Dispatching & 50 & 125 & $<5$ & 99,9 & TBD & TBD & ELM & TBD \\
\hline VII & Passenger information & 100 & 250 & $<30.0$ & 99.5 & TBD & TBD & ELM & TBD \\
\hline \multicolumn{10}{|c|}{ Infrastructure \& civil engineering, professional applications } \\
\hline VIII & Positioning of machines & $1 \mathrm{~cm}$ & TBD & $<5$ & 99.5 & TBD & TBD & Oper. Area & TBD \\
\hline $\mathrm{IX}$ & Infrastructure survey & $1 \mathrm{~cm}$ & $0.1 \mathrm{~cm}$ & $<10$ & 99 & TBD & TBD & ELM & \\
\hline $\mathrm{x}$ & Fix point applications & $5 \mathrm{~mm}$ & TBD & $<30.0$ & 99 & TBD & TBD & Fixp./ELM & TBD \\
\hline
\end{tabular}

TBD (To Be Defined) means that, for that value, no precise specification could be identified.

ELM is for European Landmass

The work on specification definition has to be performed in terms of accuracy but also in terms of safety. In the railway domain, standards define different Safety Integrity Levels (SIL1 to SIL4) to prescribe requirements for safety-related functions (realized by electrical/electronic/programmable electronic systems) to reduce and attain an acceptable risk when using this function. Requirements are not directly specified for equipment or a system, as a function can be performed with different natures of equipment: hardwarebased and/or software-based. The higher the risk is, depending on the severity of the accident that can arise when the function fails and also depending on the possible frequency of this hazard, the more the requirements are demanding and the more the SIL is high. Thus SIL-related specifications are defined, on the one hand, by qualitative measures that describe the rigor in the design and development of a system (to avoid errors, especially systematic errors arising during software design) and, on the other hand, by a scale of Tolerable Hazard Rates (THR) when failures are quantifiable. As an example, a quantitative safety target related to SIL4 is defined in the CCS TSI (Technical Specification for Interoperability relating to the Control-Command and Signaling subsystems for interoperability, [33]) with the following wording defining the target for a hazard: "for the hazard 'exceeding speed and/or distance limits advised to ERTMS/ETCS' the tolerable rate (THR) is $10^{-9} \mathrm{~h}^{-1}$ for random failures, for on-board ERTMS/ETCS and for track-side ERTMS/ETCS”. This target can then be brought to the localization function. It cannot be seen as the target for the GNSS solution, which is only a potential part of the localization function, implemented onboard the ETCS.

The consequence of the difference between aeronautical and railway requirement definitions is the difficulty for the railway users to express their needs in terms of classical positioning performances or MOPS (Minimum Operational Performance Standard) understandable by the GNSS community. [34][35][36] proposed some relationships between the communities in order to link the different criteria and help to develop RAMS methodologies [37] adapted to GNSS-based systems. [38] proposed some values of specifications of minimal quantitative requirements for GNSS systems by means of RAMS attributes.

\section{B. How to quantify required GNSS performances in the railway domain?}

Some values have been proposed as presented in table I [39] and several other proposals for the classification of applications depending on their accuracy and integrity requirements (i.e. the integrity of the localization, not the safety integrity) can be found in [40] or [41]. Most of the projects focused on the requirement expression for specific functions: GIRASOLE defined specifications for the receiver [42] or GRAIL for enhanced odometry but these are not official statements and have never been accepted as a complete list either. Table II shows the ERTMS positioning requirements translated for GNSS-based solution requirements in an ERTMS context.

Moreover, GNSS signal reception obviously differs from aviation as railway transportation is a land transportation mode and suffers from lack of signal visibility, in tunnel for example. In harsh environments, it also suffers from multipath effects and potential interferences (intentional or not). 


\section{V.REVIEW OF SOLUTIONS}

Even if not necessarily quantified, most of the solutions adopted in projects aim at ensuring the maximal availability and accuracy and/or integrity. The "or" is used here because of the different targets defined in the projects. LOCOPROL for example, highlighted the need for integrity more than accuracy on the targeted low traffic lines. In this section, the presentation is classified into availability and accuracy-related solutions first and safety-related solutions then but keeping in mind that accuracy and availability performance contribute to integrity and safety.

\section{A. How to ensure availability and accuracy?}

Everybody knows today that GNSS-alone cannot reach availability and high accuracy in constraining environments, neither a high level of safety integrity as expected for railways. Indeed, unlike a plane, a train travels close to various objects considered as obstacles for the signals: buildings, trees, cuttings or even tunnels, etc. that create multipaths or blockages of satellite signals. Thus, different solutions have been developed from classical to more original ones to co unter these effects.

[43] keeps the classical odometer-based solution and uses GNSS positioning to calibrate the odometer error when slide or slip happens. But most of the solutions of the literature rely (as for the classical road or robotics solutions) on the fusion of heterogeneous information. Their principle is to combine heterogeneous sensors in order to benefit from each one's advantages to compute PVT (Position, Velocity and Time) of the mobile. Projects like GADEROS [12] or APOLO [11] proposed multi sensor solutions that allow the system to benefit from absolute localization solutions with GPS as well as continuous and high frequency localization with the help of inertial measurements. Usual sensors are odometers but one can also find Eddy current sensors like in [44][45] and [46]. Figure 7 presents a typical architecture for a fusion in the localization unit block. [47] proposes vision-based solutions in order to detect rail tracks and switches.

Fusion techniques are discussed in [26][44][48][49] as well as fusion levels (loosely-coupled or deeply-coupled integration) in [50]. These fusion techniques are sometimes complemented with digital maps as frequently done in automotive applications [4][49][51][52][53]. [54] explains a novel double difference algorithm for train location determination that explicitly accounts for the track constraint. One shall notice that their use implies availability, accuracy, reliability, and consistency of the maps [55]. [53] evaluates the required accuracy of the map for an efficient fusion. [56] proposed a modelling scheme for generating a digital map.

In [57], the track database is not used for map-matching but, instead of a classical PVT, the train position has to be placed on the track network by topological coordinates. The coordinates are a triplet composed of the track ID, the track length and the direction of the train. The objective in this study is track selectivity.

The EATS solution, instead of usual sensors, integrates GNSS with wireless communications technology (WCT) positioning.
WCT relies on GSM-R and UMTS mobile communication systems [59] and improves in particular availability.

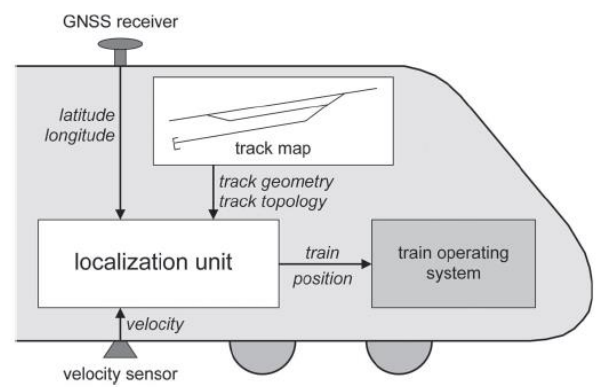

Fig. 7. Typical fusion between digital track map and the localization unit [58]

\section{B. How to ensure safety?}

Safety is ensured by specific strategies. In aeronautics, safety of the positioning is linked to integrity monitoring. Integrity monitoring ensures the user that a GNSS solution can be used as a primary navigation system in safety conditions. This monitoring can be realized by three different systems. Each of them have its own monitoring method: RAIM (Receiver Autonomous Integrity Monitoring), SBAS (Satellite-Based Augmentation System) or GBAS (Ground-Based Augmentation System). The difference between these methods is that SBAS and GBAS broadcast data usable by the receiver to compute in real time its integrity (with a protection level), while in RAIM, the receiver has to perform it alone. A posteriori, the integrity risk probability ensured using the monitoring method can also be computed.

Let's describe first the main principles of RAIM. A RAIM algorithm is contained within the receiver. It consists in performing a consistency check on the satellite measurements in order to detect a fault (an important bias observed in a pseudo-range). This check requires the reception of 5 satellites simultaneously. FDE (Fault Detection and Exclusion) is an extension of RAIM and requires 6 satellites minimum. FDE excludes the faulty satellite after its detection and allows the system to continue to ensure integrity thanks to this exclusion. RAIM inputs are the measurement noise standard deviation $\sigma_{U E R E}$, the measurement geometry, and fixed probabilities of false alarm $p_{f a}$ and missed detection $p_{m d}$. The output is either a fault detection, either a protection level $P L$, (vertical and/or horizontal), that will guarantee that the true position is contained in a circle with the given $p_{f a}$ and $p_{m d}$. The reader interested will find more details in [60] or directly in the aeronautical specifications (RTCA)[61].

In the railway-related literature, safety strategies are classified into three families of techniques.

The first family relies on redundancy. Redundancy (often with a voter) allows the system to detect incoherent measurements. In this family, GaLoROI hybridizes GNSS with an Eddy current sensor and uses architecture redundancy (with independent channels) [46] (figure 8). As in GRAIL2, the 2 channels are associated to a vote (in safe controllers) in order to check consistency between channels [62]. The GRAIL2 architecture is represented in figure 9. 


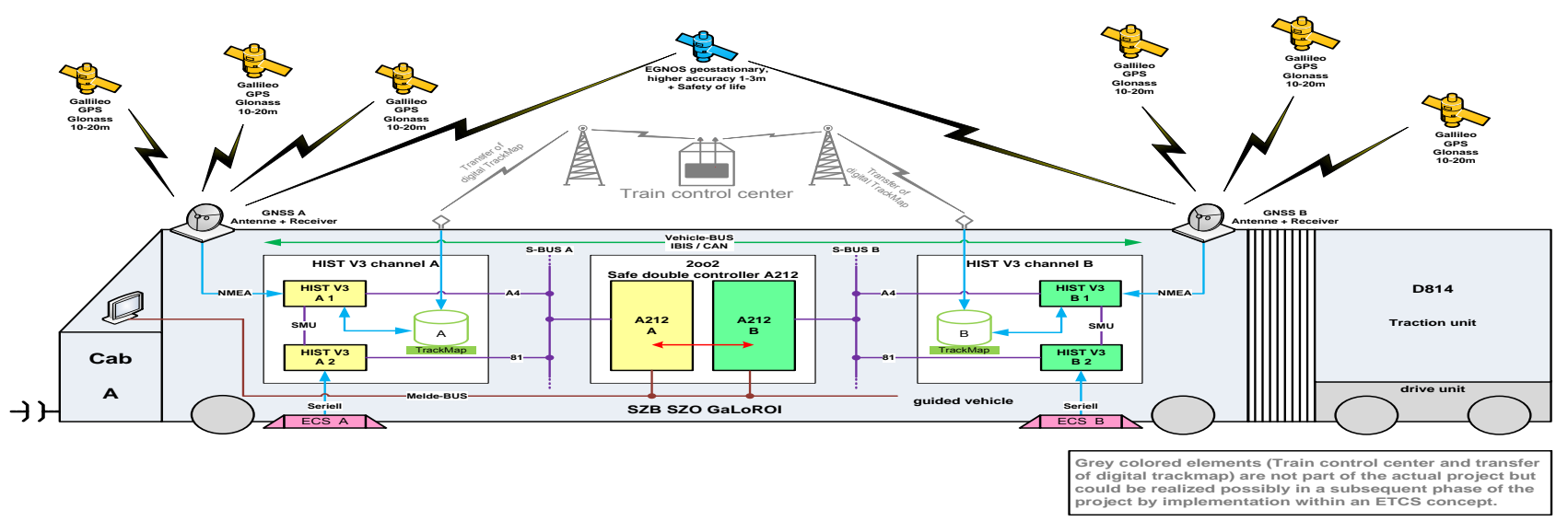

Fig. 8. GaLoROI localization unit vehicle equipment [46].

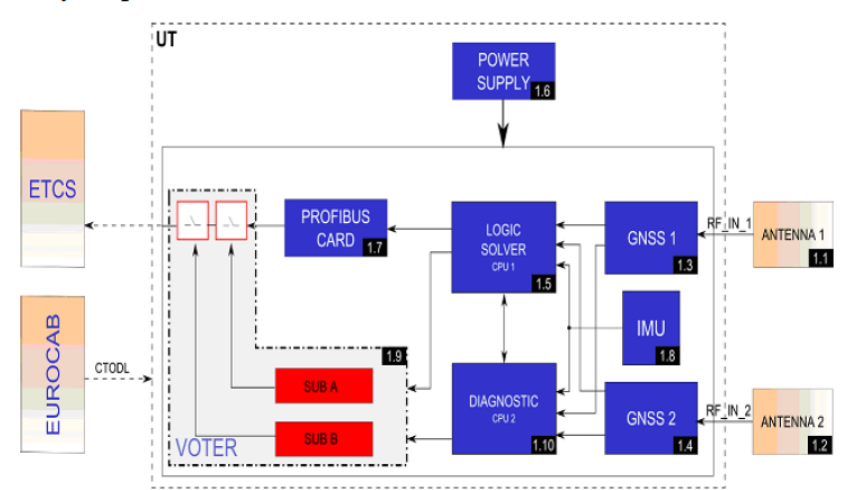

Fig. 9. SIL2 architecture of the GRAIL2 project [62].

LOCOPROL uses another form of redundancy. Indeed, instead of the redundancy of sensors or independent channels, LOCOPROL relies on the redundancy of signals, considered as independent. The original algorithm exploits, on the one hand, the 1D characteristic of a track and, on the other hand, pairs of GPS satellites assumed synchronous and redundancy of signals. Indeed, these algorithms compute positioning intervals based on TDOA (Time Difference of Arrival) techniques instead of TOA for classical solutions. TDOA has been used on pairs of GPS satellites in order to compute hyperboloid intersections with the track data base. Each pair and its intersection provide a position interval on the track. The merge of every intervals computed is made to ensure a high confidence to the final interval (PCI - Position Confidence Interval) represented in figure 10 [64].

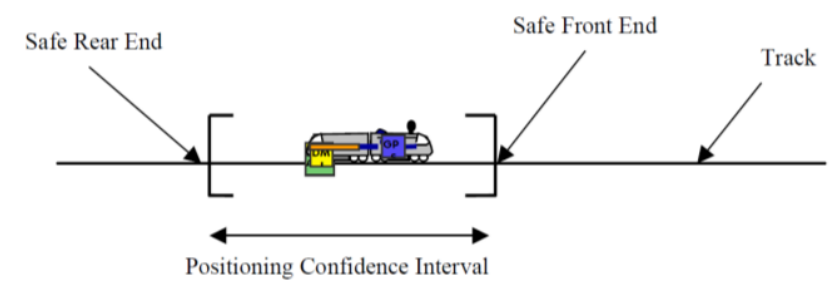

Fig. 10. The calculated position, as the union of 6 intervals (obtained from the subsets), is an interval, composed of a safe front end point and a safe rear end point [63].
The second family is based on RAIM and/or fault detection and exclusion (FDE) algorithms introduced before.

Since the early introduction of GNSS in railway, fault detection algorithms have been proposed. In 1998 [65] proposed a Fault Detection and Isolation in Multisensor Train Navigation Systems for new Automatic Train Control (ATC) and Automatic Train Protection (ATP) systems based on Chisquare test and residual test. Results of the fusion with real data have been presented in [66]. In [67], some RAIM FDE algorithms have been discussed as a complementary step for the LOCOPROL solution described previously. The LOCOPROL system provides confidence interval associated to the probability for the train to be inside the interval. The objective of a FDE is there to ensure a reasonable and usable length of the interval.

More recently, [68] implemented a fault detection and diagnosis (FDD) process for integrity insurance. Its architecture is represented in figure 11.

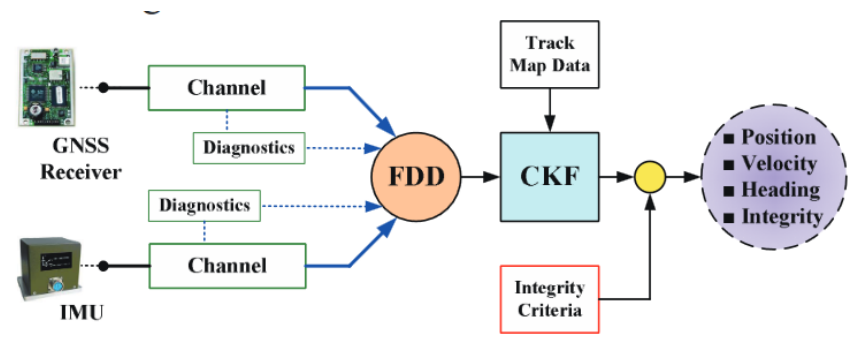

Fig. 11. High integrity architecture of GNSS/INS positioning with Fault Detection and Diagnosis based on Principal Component Analysis [68]. CKF is a cubature Kalman filter, variation of the Kalman filter.

[69] proposes an Autonomous Integrity Monitoring and Assurance (AIMA) scheme for a multisensory positioning system (accelerometer, gyroscope, odometer, GNSS). The fault detection and exclusion process is composed of three layers: before data fusion, before map-matching and before position report as summarized in figure 12 . 


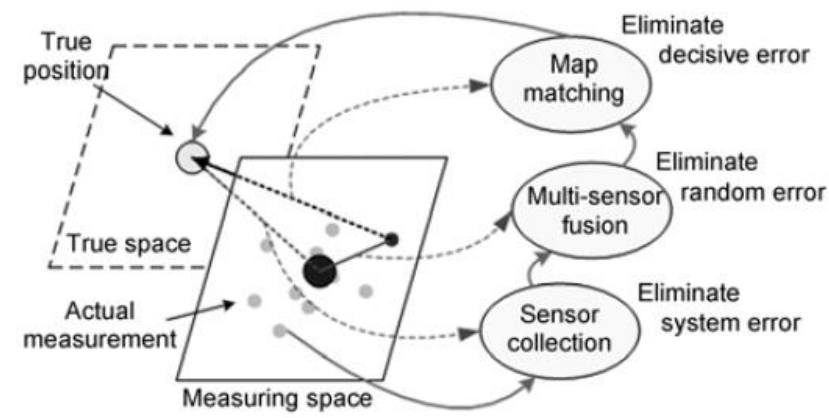

Fig. 12. Flowchart of AIMA-aided GNSS-based train integrated positioning [69].

[70] published a method for positioning errors detection based on a comparison of the GNSS-based altitude determination with the planed altitude contained in a 3D track-map. Based on simulations, he shows that GNSS errors in the horizontal plane can be detected by a test of mean (T-test) and variance (F-test) applied on vectors in an "altitude matrix".

Dealing with GNSS satellites only, [71] performs a series of checks in order to detect potentially corrupted signals or positions: weak signals rejection, use of two antennas on a coach to compare pseudo ranges, verification of the pseudo ranges by signal Doppler frequency of the carrier... [72] develops a vision-based tool capable of detecting NLOS (NonLine-of-Sight) signals. Indeed, a camera placed over the roof of the train provides images of the antenna surroundings. Early stages of this work were based on classical lenses [73]. Latest rely on a fish-eye lens that provides images of the $360^{\circ}$ surroundings of the antenna. Image processing techniques are then applied in order to classify areas in sky and non-sky areas and thus LOS or NLOS satellites as illustrated on figure 13.

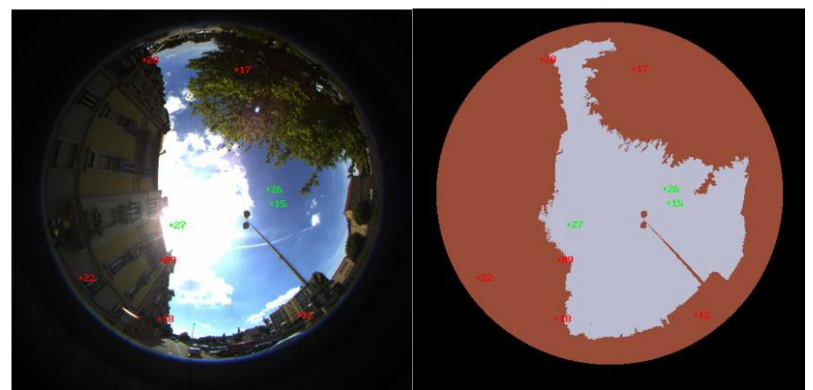

Fig. 13. Illustrations of the satellite state detection in a fisheye image on the original image and on classified regions [74].

As evoked in the perspectives of [75] in a guided-bus application, the fact that a train is guided on tracks with a prior knowledge of its trip can let us imagine that an embedded database could allow to register some pre-recorded GNSSrelated data. In this study, the idea was to record GNSS satellite availability. More recently it has been shown that a pre-knowledge of satellite-states of reception can increase accuracy of the GNSS-only solution [74]. In [76], an off-line RAIM availability prediction is proposed to compensate RAIM unavailability along the line.

The third family is based on EGNOS. EGNOS is the European SBAS system capable of providing ranging and correction data for accuracy enhancement but providing also integrity data, i.e. data to estimate the residual errors that can be expected by the users after having applied the corrections. These last data are the User Differential Range Error (UDRE) and the Grid Ionospheric Vertical Error (GIVE), commonly called 'sigmas' [77]. These two parameters can be used to determine an aggregate error, i.e. a bounded estimation of the horizontal and vertical position error that serves to compute the Protection Level (PL). EGNOS is obviously used in most of the projects, as the service is open and free. However, the EGNOS Precision Approach (PA) and Non-precision Approach (NPA) navigation modes for civil aviation were mainly designed according to specific aeronautical requirements [78]. Moreover, its availability is not optimal along railway lines. The tests performed in the LOCOPROL project, considering over $3000 \mathrm{~km}$ of rail route in Italy, showed an overall measured availability of 66\% [79]. Another example can be seen in [80]. Even if the application is roadrelated in this article, reception conditions can be very close from railway ones. The paper shows that EGNOS was received $84 \%$ of the time along the highway against around $10 \%$ in the urban context.

For terrestrial transport, the HPL (Horizontal PL), computable with the help of the EGNOS message, is of main interest and bounds the horizontal position error with a confidence level derived from the integrity risk requirement. As it relies on a Horizontal Alert Limit (AL - to be defined by users) in a defined Time To Alert (TTA), EGNOS acts for integrity monitoring and helps the localization system to declare whether its output can be used or not. As the true HPE (Horizontal Position Error) is never known, except in test or evaluation conditions with reference measurements, $H P L$ is the indicator of accuracy and is compared to $H A L$, defined by the application requirements. As summarized in figure 14, the system is declared available when $H P L<H A L$ and unavailable when $H P L>H A L$. If correctly estimated, $H P E$ should always be smaller than $H P L$ as presented in the two first cases of figure 14. The first case is the nominal case where the integrity monitoring process correctly works and the position information can be used with confidence. In the second case, the system is declared unavailable, i.e. it cannot guarantee the safety of the position. The train shall be located by another system or stopped (for safety procedure). Some operational constraints can occur but the system remains safe. However, due to non-detected failures HPE can sometimes exceed $H P L$ as illustrated in the third case. Staying below the requirements $(H A L>H P L)$ the alert will not be activated. In this third case, as the true error remains below the requirements $(H P E<H A L)$ the missed detection is not critical. But in case when $H P E$ would exceed $H A L$, a risk on integrity occurs. The occurrence of this last event has to be strongly minimized. 


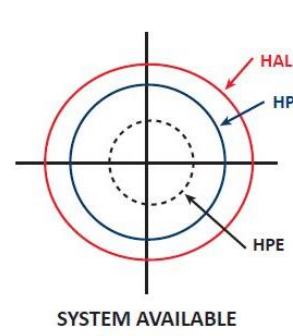
(HPL<HAL)

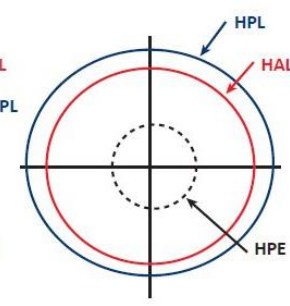

SYSTEM UNAVAILABLE (HPL $>\mathrm{HAL})$

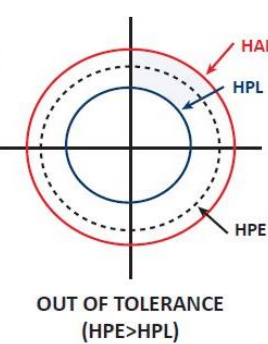

Fig. 14. Possible situations when navigating with EGNOS [77].

However, today, only the aviation domain has defined specific service requirements for EGNOS use, as well as certification and individual authorization procedures. Moreover, residuals are estimated by the Ranging Integrity Monitoring Stations (RIMS), grounds stations that do not take into account local errors, which cannot be ignored in land transport applications. Therefore, the HPL computed with EGNOS 'sigmas' cannot bound correctly the real positioning error encountered in the railway environment because of the local errors not included in EGNOS estimations. This assumption will be verified in the STARS H2020 European project (2016-2018). Note that considering an aviation solution, [78][81] showed on a static experiment that the EGNOS NPA requirements could be suitable for railway safety-related applications but this needs more experimental investigations. In road domain, a $H P L$ correctly bounding the errors (HPL $<8 \mathrm{~m})$ has been measured by [80] along highways but in the urban context, the authors illustrate that the receiver worked in safe operation mode only for $15 \%$ of the time.

For a good availability and errors computed at a very local level, a local integrity monitoring network (AIMN Augmentation and Integrity Monitoring Network) can be deployed. [82] shows that AIMN obtains a better accuracy than EGNOS. In the 3inSat project, this network includes Ranging \& Integrity Monitoring Reference Stations (RIM RS) for the purpose of integrity monitoring and accuracy improvement of satellite-based position. Each reference station provides correction services and detects systematic satellite faults [83]. [84] shows that the use of a very available augmentation network allows to reduce drastically the size of the protection level. This work will be consolidated in the RHINOS H2020 European project that aims to develop a Railway High Integrity Navigation Overlay System to be used by the user community as a combination of GNSS, SBAS and ARAIM inspired from avionics [85].

Multi-frequency as well as multi-constellation receivers are also a new field of investigation to benefit from the maximum performances of these space-based solutions.

\section{PERFORMANCES VERIFICATION}

The second challenge to use GNSS-based systems in railways is to verify that the performances obtained correspond to the requirements including safety-related ones. This section will distinguish the evaluation of positioning performances (availability, accuracy) from the safety (integrity-related) evaluation.

\section{A. How to assess performances in real railway environments?}

One of the identified tasks to be performed is to collect data in various environmental conditions so that they could cover the large diversity of reception conditions. Indeed, specifications used in the field of aviation that specify minimal environmental conditions cannot be directly transposed in the railway domain (due to satellite visibility strongly constrained by buildings, tunnels, natural obstacles like hills or trees..., as seen previously in this paper). Some other effects potentially impacting performances are electromagnetic interferences. Catenary effects have to be tested in order to be dismissed if insignificant or addressed if necessary.

Classically, the two main tools for performance evaluation are simulation and experimental campaigns. Both have advantages and drawbacks.

Simulation offers repeatability, control of all the test conditions, possibility to change the constellation (versus time and multi-constellation combinations) and anticipation of future systems (such as the complete Galileo). Furthermore, simulation can be much cheaper than intensive test campaigns. Simulation is a clear objective of the Shift2rail program, expressed as "Develop an approach for zero on-site testing using simulation tools and demonstrators in a laboratory". Some initiatives are in progress such as the ATLAS (Advanced Train LocAtion Simulator) developed by CEIT [39] and tested in the EATS project [86]. ATLAS platform aims to test various on-board location systems, with various technologies along various infrastructures.

On-site experimental campaigns are powerful for convincing users. This is the reason why most of the projects included demonstration phases with a focus on the global concept more than on the GNSS performances only. LOCOPROL experienced its solution along a rural line in Belgium, a mountainous line in South of France [72] and a high speed line in Italy [79]. SATLOC did it in Romania on a low density traffic line [87]. ERSAT EAV project, funded by GSA, begins a satellite measurement campaign in Sardinia along a double track, $50 \mathrm{~km}$ long, equipped with multi constellation receivers, with solutions for GNSS-denied area and local area augmentation network enhancing EGNOS [83][88]. For the moment, these activities mainly intended to prove the concept from a system point of view: i.e. demonstrate that the operational system can rely on a GNSS-based unit.

To our knowledge, few studies about cable interferences in railways have been published although the question of catenary effects is often asked. One can mention [89] whose one of the objectives is to focus on electromagnetic interferences from overhead cables on GPS signals. Measurements have been performed with dual frequency receivers, in a station largely surrounded by cables, also perturbed by passengers, trains etc. They did not allow to identify any effects of cable interferences. An issue for the future could be large scale verification of these electromagnetic interferences with a special task about intentional ones. The interferences are planned to be measured in the STARS H2020 European project.

Tested on simulated interferences, [90] presents an innovative radiating system based on metamaterial technology for GNSS 
reception. The solution proposed is a beam-forming adaptive antenna to be used with a GNSS receiver.

Experimental collect of GNSS data for performance evaluation has been performed in a scattered way by the different actors, in various areas, and do not make it possible today to obtain generalized error models in railway environments. A collective dataset could be an interesting tool to share in the future to fill this gap.

One of the longest dataset analyzed and published is the [91] one. RSSB (expert body in the UK that helps the rail organizations to collaborate) collected GPS and odometry data during 2008-2009 on a line close to Birmingham in order to analyze the ability of the GPS system to provide a positioning service for railways and to study GNSS dependability. They conclude that a position was computable $85 \%$ of the time, or $75 \%$ with integrity in a typical urban environment and thus, that the system requires to be complemented by other sensors or augmentation systems in order to answer railway needs. Other campaigns have been performed in China [92] in order to characterize Beidou reception along the Qinghai-Tibet Line, in a globally free of masks environment (except some tunnels). In Japan, [93] notices that in the general railroad environment, except for the dense urban areas, the association of GPS + QZSS (Quasi Zenith Satellite Solution) hardly ever has large multipath errors (more than $5 \mathrm{~m}$ ).

The combination of experimentation and simulation has been proposed in [94] in order to acquire real data but to limit the cost of experimental campaigns. In the SATLOC project, an innovative hybrid solution has also been proposed that combines experimental knowledge of the masking obstacles with a GNSS signal simulator [95]. The interest of the approach is to reproduce a trajectory and its associated reception conditions with obscuration. Then a scenario can be repeated or replayed with many different parameters (satellite constellations, atmospheric conditions, multipath, interferences etc.) but without the need to go back in operation onto the railway line.

For road ITS (Intelligent Transportation Systems), in order to prepare context for certification of new applications, the COST action SaPPART ${ }^{1}$ discusses the needs to propose common methodologies for performance validation. In aeronautics, applications are classified into worldwide agreed performance objectives. A challenge for railways will be in the close future to decide whether such certification context and agreed performances are relevant and useful to define. This is one of the topics of Shift2Rail, UNISIG working groups and other entities regrouping the stakeholders.

The certification issues have been explored in the GaLoROI project. [96] describes a general safety case structure for certification that will have to be based on a normative background, not defined for railway safety applications of GNSS today.

\section{B. How to prove GNSS-based solution safety and with which safety target?}

The last but not the least task is the safety proof of a GNSSbased solution for railways.

\footnotetext{
${ }^{1}$ http://sappart.net/
}

Today, aeronautics uses EGNOS-based solutions in more than 170 airports all over Europe as alternative equipment to conventional instrument for landing in safety. Safety cases have been performed in order to authorize these procedures and this shall be done also by railway actors.

In railways, a safety case has to demonstrate that the new product satisfies dependability and safety conditions using especially RAMS requirements as defined in the three European railway standards EN50126 [97], EN50128 [98] and EN50129 [99] (notice that the $1^{\text {st }}$ and the $3^{\text {rd }}$ will be soon replaced by revised versions). ERA (European Railway Agency) is responsible for managing common European railway rules and specifications through different legal texts composed of directives, decisions and regulations. Four parties are also involved when assessing the safety of a system [100]:

- the proposer of the new system,

- (one or several) independent assessment body (ISA Independent Safety Assessor),

- a rail notified body (NoBo),

- a National Railway Safety Authority (NSA).

The aim of an ISA is to audit, assess and review processes and safety evidences generated along the life-cycle of a project, in order to ensure and demonstrate compliance to safety standards and suitable techniques and to assess the adequacy of the evidence [101]. Notified bodies by the different member states to the EU Commission are third parties, independent of organization or product. They assess and perform conformity assessment pursuant to the European texts and give certificate of conformity. The NSA gives the final authorization to use the product in operation.

A function that participates in the traffic safety, like the localization function, can potentially lead to a catastrophic consequence if a failure occurs. According to the regulation 402/2013/UE [102] (amended by the implementing regulation (EU) 2015/1136), the hazard rate requirement in this case "does not have to be reduced further if the rate of that failure is less than or equal to $10^{-9}$ per operating hour". Also, as mentioned before, the CCS TSI allocates a THR equal to $1.0 \times 10^{-9}$ failure/hour to the on board ETCS failure. It is important to consider that this target cannot be directly allocated to the GNSS receiver but to the global localization function realized by all subsystems. Indeed, recent projects agreed that the target for the GNSS-based positioning subsystem is SIL2 as in GRAIL-2 [62], or SATLOC [88]. However some others expressed higher safety levels, as GaLoROI, that targets SIL3 [46] and previously LOCOPROL a SIL4 [63] but with low accuracy constraints.

To our knowledge, the deeper demonstration on this point has been performed in the GRAIL-2 project [103]. In this project, deliverable D4.2 (public document) aimed at demonstrating compliance with the Railway Safety Approval process by carrying out an Independent Safety Assessment of GRAIL-2 system in order to assess the correct use of the methodology stated by the EN standards to demonstrate safety. In GRAIL-2, Bureau Veritas performed an assessment report based on the documentation officially delivered by the partners of GRAIL2 Consortium and through meetings with the parts involved. The SIL 2 demonstration relies on the evaluation of the accuracy measure in fault free conditions, the evaluation of the effects 
of random failures belonging to the satellite system and the evaluation of the effects of random failures belonging to the GNSS unit. In absence of specific railway regulation for the use of GNSS, avionic regulations have been applied when compliant and adapted to take into account some specificities of railway as multipath effects, protection levels along the track or train kinematic [103]. The ERSAT project [100] is following the same steps also and RFI shall submit to ANSF (The Italian safety authority) the request to release the authorization to put the system into service. The request will be composed of preliminary hazard analysis, draft operational rules, the intervention of an independent safety assessor.

These validations were inspired from aviation as there are no railway methodologies completely operational. In particular, usual RAMS methods are not adequate for wireless systems in general and thus for GNSS-based positioning systems. The next section will explain why and will focus on recent RAMS evaluation approaches that seek to overcome this methodological issue.

\section{How to evaluate RAMS of a GNSS-based solution?}

The RAMS evaluation of an LDS (Location Determination System) strongly depends on the complexity of its architecture (number and heterogeneity of its constituents, various interactions between them that generate dependencies) and its context of operation. The architectures of the embedded GNSS-based LDS can be composed of three types of constituents (cf. section V):

- Hardware constituents (GNSS, odometer, Inertial Navigation System, etc.), whose output signals give location data,

- Digital data used to improve location data; they come from track database and/or from satellite augmentation systems,

- Software algorithms for, on the one hand, fusing the heterogeneous information coming from both previous physical and logical data sources and, on the other hand, detecting fault.

These elements can also be redundant (e.g. simple redundancy of sensors, redundant channels with a $M$ out of $N$ structure). Today most of the LDS design strategies comprise at least a hybrid core without redundancy. The hybridization with other sensors is for compensating masking environments that disturb signals.

LDS with a standalone GNSS receiver was still analyzed in [37] to show how, with a proposed procedure based on measurements recorded in conditions of operation, RAMS properties can be quantified. Two failure modes were considered with the states $S t_{1}$ "estimated position outside accuracy tolerance boundaries" and $S t_{2}$ "position not delivered due to insufficient number of signals received". Another approach with the same considered failure modes relies on a Petri-Net model that enables to quantify, by simulation, the same properties but considering besides specific GNSS quality criteria (HDOP, signal to noise ratio) [104]. [28] introduced an additional degraded mode to identify positions with degraded accuracy but that still can be used for train localization, and considered a faulty state that combined in fact $S t_{1}$ and $S t_{2}$ (the up/degraded/faulty states and their associated values are defined in table III, $\delta t$ is the position error). The probabilities associated to the failures modes were then empirically quantified and, given a proposed translation of some GNSS criteria (e.g. accuracy, trueness, continuity) into reliability, availability and hazardous rate, railway properties have been evaluated. The results of these approaches in different zones like tunnels, urban, wooded and railway cutting environments show that the localization function based on GNSS alone is far to reach the safety requirements and needs risk reduction measures to overcome GNSS outage situations (such as the use of redundant systems or the use of fault detection systems). Moreover, they did not consider any type of hardware or software failures coming from the user equipment (the GNSS receiver was assumed operating correctly) or from the satellite equipment (the signal data were assumed to be not corrupted as no detection mechanisms, as those presented in section 5.B, were employed). These studies show that the effect of signal propagation delays on position uncertainties is a very impacting element to be considered in RAMS studies. However classical dependability techniques and methods (such as Fault Trees, Reliability Block Diagrams, Markov Analysis) are not ready for that. 

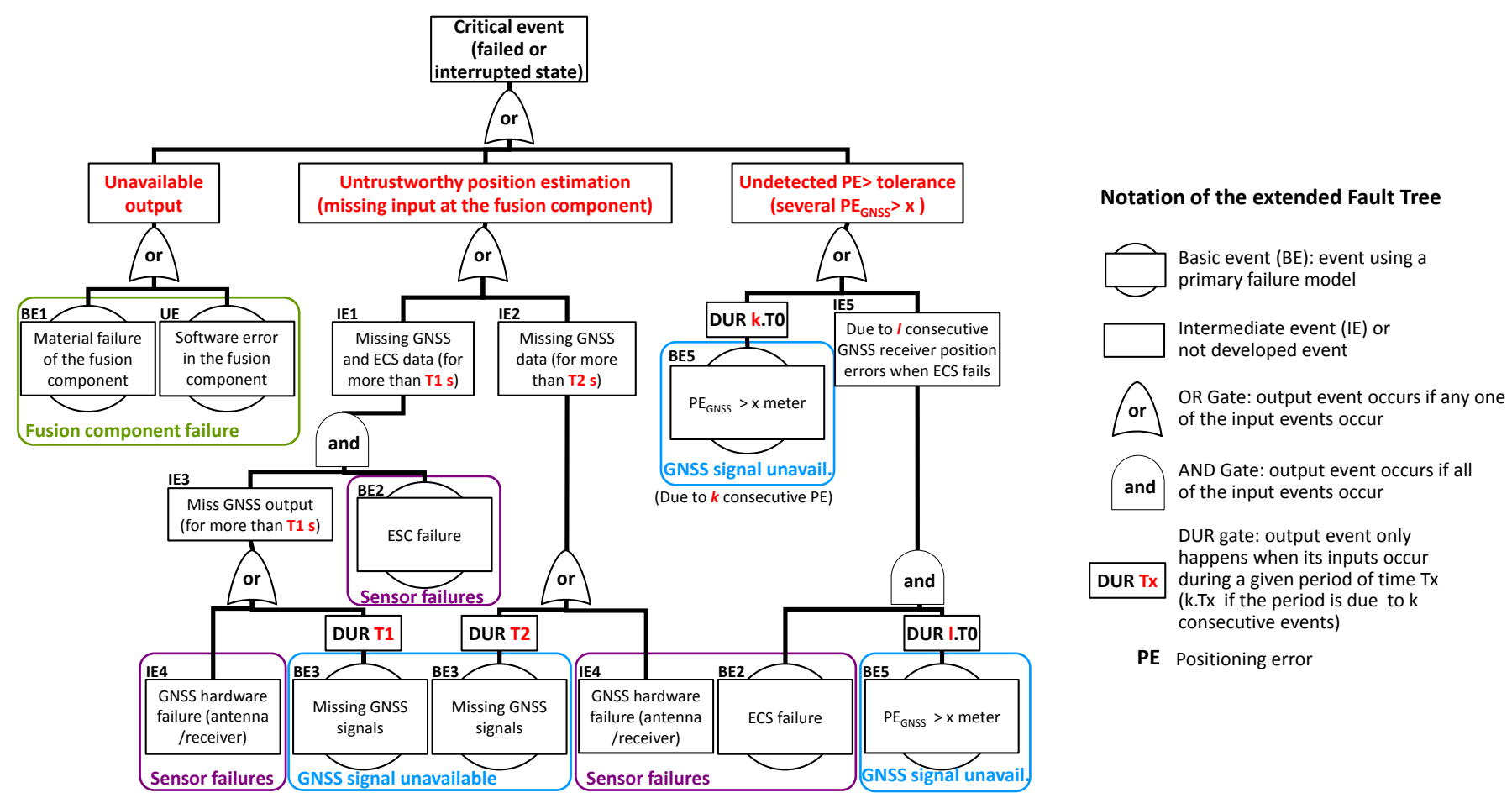

Fig. 15. eFT of GNSS and ECS based localization unit adapted from [105].

TABLE III. STATES AND RELATED ACCURACY REQUIREMENTS BY [28]

\begin{tabular}{ll}
\hline States & Requirements \\
\hline Up State & $\delta_{t} \leq 10 \mathrm{~m}$ and $H D O P_{t} \leq 6$ \\
Degraded State & $10 m \leq \delta_{t} \leq 20 \mathrm{~m}$ and $H D O P_{t} \leq 6$ \\
Faulty State & $20 m<\delta_{t}$, or $H D O P_{t}>6$, or $\nexists \delta_{t}$ \\
\hline
\end{tabular}

An evaluation methodology is proposed in [105] to analyze LDS with a hybrid core, in particular the GaLoROI solution, which mainly relies on two material components: GNSS + ECS sensors hybridized with a fusion algorithm. Unlike above studies, hardware failure rates are considered for the equipment. The dependencies between failure modes is also considered, i.e. when a data source is missing due to a fault, the other alone has a greater effect on position error so the critical event 'position error>tolerance' can occur faster. Therefore, to face with such complex system with timedependent states, the first objective of the authors was to propose a technique to model in a comprehensive way the dynamic behavior of the components and their faults. The extended Fault Tree (eFT) method has therefore been developed. The second objective was to evaluate RAMS properties using the eFT model of the system. This one is represented in figure 15 where the event definitions appear clearly. The relations between these events are here simplified using classical logical gates (AND, OR) and one type of dynamic gate (DUR-duration- gate). This eFT is then translated following specific rules [106] into a Petri Net model whose transitions integrate appropriate failure probability distributions. The PN can finally be executed with a dedicated simulation tool. The results of [105] show that this GNSS \&
ECS structure does not satisfy the availability requirement, especially in the woody environment, and that it has to be improved using redundant sensor channels as it has been done in the project using the composite fail-safe technique [99]. A $\mathrm{PFH}$ value (probability of a dangerous failure during 1 hour) related to SIL 3 has been proved only if the system parameters $k, l, T 1$ and $T 2$ (cf. figure 15) are inside given intervals. These intervals have been obtained theoretically with simulated data and should be verified with on-site tests. The modelling and simulation tasks become very complicated when the LDS is coupled with a detection mechanism.

For LDS with a hybrid core and a detection system, rather than doing evaluations through a model that is hard to obtain when trying to formalize signal processing aspects, [107] focused on what has been done in the aeronautical domain. In particular, the authors concentrate on the techniques to evaluate the integrity risk when a detection mechanism is used. Thus a quantitative safety evaluation is proposed through the determination of the integrity risk associated to the system by defining an extended integrity risk concept. It is demonstrated how to evaluate the safety of the LDS, as expected in railways, with this concept. In [108], a case study with a simple GNSS/INS system has been simulated in order to determine the SIL level of this solution. The GNSS/INS localization system reaches the integrity risk of $9.77 \times 10^{-5}$. A $\mathrm{PFH}$ deduced from this integrity risk is estimated at $1.34 \times 10^{-6}$ failure per hour, corresponding to a SIL1.

Railway operational context of LDS was analyzed in [109] and can be seen as a pre-requisite for RAMS evaluation. In this paper, the authors concentrate on the way to obtain a verifiable model for a satellite-based system used in a train control system. For that, the authors propose a scenario-based modeling approach using a CPN (Colored Petri Nets) model, 
which has a hierarchical structure to make readable formal descriptions of ETCS operational scenarios integrating satellite-based location data (these data are considered without error in the article).

\section{CHALLENGING ISSUES AND FUTURE RESEARCH NEEDS}

GNSS for railways is investigated since more than 15 years now. A number of technical solutions have been developed and demonstrated through these years that have increased awareness of the potentialities and the interest of such systems for future railways. Some real advances are noticed. As a conclusion of this survey, this section highlights the main remaining issues considering the work already done.

\section{A. Demonstrate the cost-benefit}

The number of interested operators grows: RFI (Italy), DB (Germany), Network Rail (UK) or SNCF (France) seem to investigate seriously the gain that could be brought by changing the equipment. For the Italian lines, cost-benefit analyses have already been realized [15] that clearly confirmed that railways need GNSS in particular if we look at the required investment to be performed for ERTMS deployment (more than $1 \mathrm{~b} €$ economy). [8] demonstrates, with a System Dynamics Model, that a first market adoption of the SATLOC solution is expected after 36 months of product introduction by railway suppliers. This demonstrated benefit for the railway operators will keep the door wide open to future researches and would speed up the developments. The generalization of these studies to enlarge the number of convinced potential users remains an issue as many of them still feel reticent about migrating to GNSS.

The calendar is driven by two calendars: the railway one, devoted to ERTMS Technical Specifications for Interoperability (TSIs) releases, and the GNSS one, with the EGNOS evolution.

\section{B. Experiment GNSS in railway environments}

With the deployment of new GNSS constellations (Galileo, Beidou), projects of the near future will rely on multiconstellation solutions. European projects are looking towards Galileo benefits [25][36]. Chinese solutions such as [110] will study the impact of GPS and Compass (Beidou)-based solutions. Japanese lines will benefit from QZSS from 2018 [71]. The benefits of multi-constellation will give better accuracy, availability and also robustness [111][112].

Some technical issues remain that have to be investigated in this context: economical, temporal, European, cultural... Some technological issues have been mentioned in this paper that deal with the fact that trains run on the ground and that GNSS suffers from masking effects, multipath, interferences... Even if number of the past projects experienced GNSS reception on running trains, measurements of signal reception and positioning performances on a large scale, as the STARS project is planning to do, should quickly provide an evaluation of the performances available in a real environment. Moreover, experimentation is essential for the users to become familiar with this new technology.

The more acceptable the evaluated GNSS performances will be, the more adequate the proposed solutions will be. The hybrid solution to be embedded in trains shall answer the requirements without embedding inappropriate or unnecessary sensors.

Error modeling will allow to bound errors in these environments as it has been done in the past in aviation. These bounds are of main importance for integrity concepts. Indeed, the knowledge of uncertainties is the guarantee of protecting the system against undesirable errors.

\section{Define requirements}

Requirements are today defined heterogeneously in the different projects. The definition in progress of the MOPS will offer a visibility to the navigation suppliers on the railway needs and the possibility to quantify the gap to answer the railway requirements. In particular, to prepare the next generation of EGNOS and its usage in the railway domain, one of the tasks to be performed in the short term is to define the required railway MOPS. That will make them understandable by the GNSS community more familiar with aeronautics than rail.

\section{Demonstrate safety}

Adapted assessment methods are developed to adapt traditional RAMS evaluations to the wireless characteristics of satellite signals and quantify the added value of GNSS integrity. This topic is still quite new. In this paper, we have shown that new methodologies have been proposed in the recent years that need to be applied on real operational scenarios. Moreover, the step beyond will be the certification and if doors are opened in this direction, the work is still to be done.

\section{E. Experiment on operational lines}

As expressed in paragraph $\mathrm{B}$, experimentations are necessary to take in hand the technology and its behavior in the real railway environment. But one has also to think that, in parallel, pilot lines need to be equipped in order to evaluate their impact on the operational rules and provide the necessary elements for safety cases.

\section{F. Prepare certification}

Last but not least, the certification issue has been introduced in section VI B. Some preliminary studies have been performed such as the one of the GaLoROI project [96]. Certification is one of the biggest and shortest term issue identified in the ERSAT project also that requires involving NSAs and, in the close future, the European Railway Agency.

The penetration of GNSS in the railway signaling can still be long, but has reached today a certain level of maturity that organizes the railway stakeholders in a dynamic circle. This aims to make possible that user needs encounter spatial potential. GNSS in railway for safety-related applications is now seriously considered by the different stakeholders of the railway chain: signaling manufacturers, infrastructure managers, or operators. 


\section{REFERENCES}

[1] Minary, B., Lozac'h, J.P. (2006). Tr@in-MD: the intelligent railway transport for hazardous goods, In Proceedings of the 7th World Congress on Railway Research, Montréal, Canada.

[2] Stadlmann, B. (2006, September). Automation of operational train control on regional branch lines by a basic train control system. In Intelligent Transportation Systems Conference, 2006. ITSC'06. IEEE (pp. 50-54).

[3] Durazo-Cardenas, I., Starr, A., Tsourdos, A., Bevilacqua, M., \& Morineau, J. (2014). Precise Vehicle Location as a Fundamental Parameter for Intelligent Self-aware Rail-track Maintenance Systems. Procedia CIRP, 22, 219-224.

[4] Albrecht, T., Luddecke, K., \& Zimmermann, J. (2013, August). A precise and reliable train positioning system and its use for automation of train operation. In Intelligent Rail Transportation (ICIRT), 2013 IEEE International Conference on (pp. 134-139).

[5] Dhahbi, S., Abbas-Turki, A., Hayat, S., \& El Moudni, A. (2011, May). Study of the high-speed trains positioning system: European signaling system ERTMS/ETCS. In Logistics (LOGISTIQUA), 2011 4th International Conference on (pp. 468-473). IEEE.

[6] Roca, J., \& Perez, J. L. (1997). All aboard! On track with Catalonia's trains. GPS World.

[7] Acil Allen Consulting, Precise positioning services in the rail sector, Report, June 2013.

[8] Hosse, R. S., Manz, H., Burmeister, K., \& Schnieder, E. (2014, April). Market analysis for satellite train localisation for train control systems. In Transport Research Arena (TRA) 5th Conference: Transport Solutions from Research to Deployment.

[9] Neri, A., Rispoli, F., \& Salvatori, P. (2015). An analytical assessment of a GNSS-based train integrity solution in typical ERTMS level 3 scenarios. In Proceedings of ENC 2015.

[10] Raymond, G., Marais, J., Berbineau, M. (2004) Innovations Bring Satellite Control within Reach, Railway Gazette International, Déc. 2004, p835-837.

[11] Filip, A., Bažant, L., Mocek, H., Taufer, J., \& Maixner, V. (2001). Architecture of GNSS aided signalling: Analysis and experiments. In Proceedings of Word Congress on Railway Research (WCRR).

[12] Urech, A., Pérez Diestro, J., \& Gonzalez, O. (2002, July). GADEROS, a GAlileo Demonstrator for Railway Operation System. In Data Systems in Aerospace (Vol. 509, p. 46).

[13] Mertens, P., \& Franckart, J. P. (2003). Low-cost signalling on Lowdensity lines. Railway Gazette International.

[14] Manz, H., Schnieder, E., Becker, U., Seedorff, C., \& Baudis, A. (2014, April). Approach to Certification of Satellite Based Localisation Unit in Railways. In Transport Research Arena (TRA) 5th Conference: Transport Solutions from Research to Deployment.

[15] Rispoli, F., Neri, A., \& Senesi, F. (2014). Innovative train control systems based on ERTMS and satellite-public TLC networks. Computers in Railways XIV: Railway Engineering Design and Optimization, $135,51$.

[16] Albanese, A., Marradi, L., Campa, L., \& Orsola, B. (2004). The RUNE project: navigation performance of GNSS-based railway user navigation equipment. In Proceedings of NAVITEC.

[17] Facchinetti, C., Ansalone, L., \& Tuozzi, A. (2015, October). Trends in GNSS Italian application scenarios in transportation. In Navigation World Congress (IAIN), 2015 International Association of Institutes of (pp. 1-8).

[18] ERTMS MoU, Memorandum of Understanding between the European Commission, The European Railway Agency and the European Rail sector Associations concerning the strengthening of cooperation for the management of ERTMS. 12/04/2012.

[19] Joint Council on Transit Wireless Communications. Positive Train Control - White Paper - May 2012.

[20] Badugu, S., Movva, A. (2013). Positive Train Control, in International Journal of Emerging Technology and Advanced Engineering, Volume 3, Issue 4, April 2013, pp304-307.

[21] Betts, K. M., Mitchell, T. J., Reed, D. L., Sloat, S., Stranghoener, D. P., \& Wetherbee, J. D. (2014, May). Development and operational testing of a sub-meter Positive Train Location system. In Position, Location and Navigation Symposium-PLANS 2014, 2014 IEEE/ION (pp. 452-461).

[22] Wullems, C. (2011). Towards the adoption of low-cost rail level crossing warning devices in regional areas of Australia: A review of current technologies and reliability issues. Safety science, 49(8), 10591073.

[23] Ning, B., Tang, T., Qiu, K., Gao, C., \& Wang, Q. (2004). CTCS-Chinese train control system. Advanced Train Control Systems, 1.

[24] Winter, J., Gu, X., \& Schmidt, M. (2000). Energy optimised driving style management using a satellite-based train positioning platform. In International conference on computers in railways (pp. 1301-1307).

[25] Strang, T., Meyer zu Hörste, M., \& Gu, X. (2006, October). A railway collision avoidance system exploiting ad-hoc inter-vehicle communications and Galileo. In Proceedings of the 13th World Congress and Exhibition on Intelligent Transportation Systems and Services (ITS 2006), London, UK.

[26] Acharya, A., Sadhu, S., \& Ghoshal, T. K. (2011). Train localization and parting detection using data fusion. In Transportation Research Part C: Emerging Technologies, 19(1), 75-84.

[27] Lin, J., Wang, X., \& Dang, J. (2014). Reliability and safety verification of the new collision avoidance strategy for Chinese train control system. In computer modelling \& new technologies, 18(9) 415-422.

[28] Lu, D., \& Schnieder, E. (2015). Performance evaluation of GNSS for train localization. In Intelligent Transportation Systems, IEEE Transactions on, 16(2), 1054-1059.

[29] Fraile, J. M. (2000). Advanced GNSS-based localization system for railway applications. In proceedings of the 7 th world congress on Intelligent Systems, Turin.

[30] Lauer, M., \& Stein, D. (2013, August). Algorithms and concepts for an onboard train localization system for safety-relevant services. In Intelligent Rail Transportation (ICIRT), 2013 IEEE International Conference on (pp. 65-70).

[31] Marradi, L., Albanese, A., \& Di Raimondo, S. (2008). RUNE (Railway User Navigation Equipment): Architecture \& Tests. In Satellite Communications and Navigation Systems (pp. 461-479). Springer US.

[32] GNSS Rail user forum, Requirements of rail applications, 2000.

[33] Decision CCS TSI - 2012/88/UE (2012). Technical specification for interoperability relating to the control-command and signalling subsystems of the trans-European rail system. European Commission. Amended by Decisions 2012/696/EU and (EU) 2015/14.

[34] Filip, A., Mocek, H., \& Suchanek, J. (2008, May). Significance of the Galileo Signal-in-Space Integrity and Continuity for Railway Signalling and Train Control. In 8th World Congress on Railway Research (WCRR), Seoul, Korea.

[35] Filip, A., Beugin, J., Marais, J., Mocek, H. (2008). A relation among GNSS quality measures and railway RAMS attributes, in CERGAL 2008, Braunschweig.

[36] Beugin, J., Filip, A., Marais, J., \& Berbineau, M. (2010). Galileo for railway operations: question about the positioning performances analogy with the RAMS requirements allocated to safety applications. In European Transport Research Review, 2(2), 93-102.

[37] Beugin, J., \& Marais, J. (2012). Simulation-based evaluation of dependability and safety properties of satellite technologies for railway localization. Transportation Research Part C: Emerging Technologies, $22,42-57$

[38] Mocek, H., Filip, A., \& Bazant, L. (2010). Galileo Safety-of-Life Service Utilization for Railway Non-Safety and Safety Critical Applications. Journal of Mechanical Systems for Transportation and Logistics, 3(1), 119-130.

[39] Goya, J., Zamora-Cadenas, L., Arrizabalaga, S., Brazález, A., Meléndez, J., \& Mendizabal, J. (2015). Advanced Train Location Simulator (ATLAS) for developing, testing and validating on-board railway location systems. In European Transport Research Review, 7(3), 1-18.

[40] Filip, A., Polivka, A., \& Suchánek, J. (2006, June). Practical Analysis of Satellite Navigation Performance for Train Control. In 7th World Congress on Railway Research, Montréal (WCRR'2006), Canada.

[41] Thomas, M., Savopoulos, A., Powe, M., (2006). Safety applications and the requirements background. Deliverable of the GRAIL project.

[42] GIRASOLE, (2005). Receiver specification for railway applications. Deliverable 2.1 of the GIRASOLE project.

[43] Bai-gen, C., Jian, W., Qin, Y., \& Jiang, L. (2009, July). A GNSS based slide and slip detection method for train positioning. In Information Processing, 2009. APCIP 2009. Asia-Pacific Conference on (Vol. 1, pp. 450-453). IEEE.

[44] Böhringer, F., \& Geistler, A. (2006, September). Comparison between different fusion approaches for train-borne location systems. In Multisensor Fusion and Integration for Intelligent Systems, 2006 IEEE International Conference on (pp. 267-272). IEEE. 
[45] Hensel, S., Hasberg, C., \& Stiller, C. (2011). Probabilistic rail vehicle localization with eddy current sensors in topological maps. In Intelligent Transportation Systems, IEEE Transactions on, 12(4), 1525-1536.

[46] Manz, H., Schnieder, E., Stein, D., Spindler, M., Lauer, M., Seedorff, C., Baudis, A., Becker, U., Beugin, J., Nguyen, T.P. K., Marais, J., (2015). GaLoROI: Satellite based localization in railways, In International congress on advanced railway engineering, Istanbul, March 2-5 2015

[47] Wohlfeil, J. (2011). Vision based rail track and switch recognition for self-localization of trains in a rail network. In Intelligent Vehicles Symposium (IV), 2011 IEEE (pp. 1025-1030).

[48] Gao, S. S., Sang, C. M., \& Li, W. (2009). Application of improved particle filter to integrated train positioning system [J]. Journal of Chinese Inertial Technology, 6, 018.

[49] Lüddecke, K., \& Rahmig, C. (2011, June). Evaluating multiple GNSS data in a multi-hypothesis based map-matching algorithm for train positioning. In Intelligent Vehicles Symposium (IV), 2011 IEEE (pp. 1037-1042).

[50] Wang, J., Yan, X. H., Cai, B. G., \& Shangguan, W. (2011, November). Research on deeply integrated GPS/INS for autonomous train positioning. In Proceedings of IEEE 4th International Symposium on Microwave, Antenna, Propagation, and EMC Technologies for Wireless Communications 2011 (pp. 687-690).

[51] Saab, S. S. (2000). A map matching approach for train positioning. I. Development and analysis. In Vehicular Technology, IEEE Transactions on, 49(2), 467-475.

[52] Liu, J., Cai, B. G., \& Wang, J. (2014, October). A GNSS/trackmap cooperative train positioning method for satellite-based train control. In Intelligent Transportation Systems (ITSC), 2014 IEEE 17th International Conference on (pp. 2718-2724).

[53] Zheng, Y., \& Cross, P. (2012). Integrated GNSS with different accuracy of track database for safety-critical railway control systems. GPS solutions, 16(2), 169-179.

[54] Neri, A., Palma, V., Rispoli, F., \& Vegni, A. M. (2013, September). Track constrained PVT estimation based on the double-difference technique for railway applications. In Proceedings of the 21st European Signal Processing Conference (EUSIPCO), 2013 (pp. 1-5).

[55] Gerlach, K., \& Hörste, M. M. Z. (2009, October). A precise digital map for GALILEO-based train positioning systems. In Intelligent Transport Systems Telecommunications,(ITST), 2009 9th International Conference on (pp. 343-347).

[56] Böhringer, F., \& Geistler, A. (2006). Location in railway traffic: Generation of a digital map for secure applications. In Computers in Railways X. The Tenth International Conference.

[57] Heirich, O., Robertson, P., García, A. C., Strang, T., \& Lehner, A. (2012, June). Probabilistic localization method for trains. In Intelligent Vehicles Symposium (IV), 2012 IEEE (pp. 482-487). IEEE.

[58] Lauer, M., \& Stein, D. (2015). A Train Localization Algorithm for Train Protection Systems of the Future. In Intelligent Transportation Systems, IEEE Transactions on, 16(2), 970-979.

[59] Zheng, Y., Hutchinson, M., Lowe, D., Arrizabalaga, S., Goya, J., Zamora-Cadenas, L., Valera, J., Sanchez J. (2016). The hybrid GNSS/WCT multi-coach multi-constellation train positioning and integrity system. In Proceedings of the 2016 International Technical Meeting, ION ITM 2016, January 25-28 Monterey, California.

[60] Kaplan, E., \& Hegarty, C. (2006). Understanding GPS: Principles and Applications Second Edition.

[61] RTCA (2010) Minimum operational performance standards for global positioning system/wide are augmentation system airborne equipment. RTCA SC-159, DO-229D, Washington, DC.

[62] Marradi, L., Galimberti, A., Foglia, L., Zin, A., Pecchioni, C., Doronzo, M. \& Lekchiri, M. (2012, December). GNSS for Enhanced Odometry: The GRAIL-2 results. In Satellite Navigation Technologies and European Workshop on GNSS Signals and Signal Processing,(NAVITEC), 2012 6th ESA Workshop on (pp. 1-7).

[63] Lancien, D., Rousseau, M., Franchineau, J.L., Castan, P., Ryckebosch, H., Droste, A., Marais, J. (2005). LOCOPROL Deliverable D 6.2, Compiled evaluation results.

[64] Marais, J., Berbineau, M., Frimat, O., \& Franckart, J. P. (2003, December). A new satellite-based fail-safe train control and command for low density railway lines. In TILT Seminar (Technological Innovations for Land Transportation), Lille, France.

[65] Mirabadi, A., Mort, N., \& Schmid, F. (1998, September). Fault detection and isolation in multisensor train navigation systems. In Control'98.
UKACC International Conference on (Conf. Publ. No. 455) (pp. 969974).

[66] Mirabadi, A., Schmid, F., \& Mort, N. (2003). Multisensor integration methods in the development of a fault-tolerant train navigation system. The Journal of Navigation, 56(03), 385-398.

[67] Nikiforov, I. V., Choquette, F., \& Belgium, A. T. (2003, April). Integrity Equations for Safe Train Positioning Using GNSS. In Proceedings of GNSS 2003-The European Navigation Conference.

[68] Jiang, L., Bai-Gen, C., Tao, T., \& Jian, W. (2010, August). A CKF based GNSS/INS train integrated positioning method. In Mechatronics and Automation (ICMA), 2010 International Conference on (pp. 16861689).

[69] Liu, J., Tang, T., Gai, B., Wang, J., \& Chen, D. (2011). Integrity assurance of GNSS-based train integrated positioning system. Science China Technological Sciences, 54(7), 1779-1792

[70] Jonas, M. (2014, May). Integrity enhancement of the GNSS position solution for the railway applications. In Position, Location and Navigation Symposium-PLANS 2014, 2014 IEEE/ION (pp. 83 9-845).

[71] Yamamoto, H., Takasu, T., \& Kubo, N. (2015). Satellite Based Train Positioning Using Three-dimensional Track Maps. Quarterly Report of RTRI, 56(3), 194-199.

[72] Marais, J., Flancquart, A., \& Lefebvre, S. (2006). Satellite availability in a railway mountainous environment: Can we use satellite positioning for safety applications? In World Congress on Railway Research (WCRR), Montréal.

[73] Marais, J., Meunier, B., \& Berbineau, M. (2000). Evaluation of GPS availability for train positioning along a railway line. In Vehicular Technology Conference, 2000. IEEE-VTS Fall VTC 2000. 52nd (Vol. 5, pp. 2060-2067).

[74] Marais, J., Tay, S., Flancquart, A., Meurie, C. (2015). Weighting with the pre-knowledge of GNSS signal state of reception in urban areas, In Proceedings of ENC GNSS 2015, 9 avril 2015, Bordeaux.

[75] Marais, J., Girard, P. L., Prestail, A., Franchineau, J. L., \& De Verdalle, E. (2007, June). Galileo availability for urban buses. In Telecommunications, 2007. ITST'07. 7th International Conference on ITS (pp. 1-5).

[76] Liu, J., Gai, B., Wang, J., Shangguan, W. (2015) Estimating the Integrity of BDS-based Positioning for Rail Vehicles in Signaling Applications. In proceedings of CERGAL, Darmstadt, Germany.

[77] GSA - The European GNSS Agency, EGNOS Safety of Life (SoL) Service Definition Document, Sept. 2015.

[78] Filip, A. (2010, April). Which of EGNOS Navigation Modes for Railway Signalling: Precision Approach or En Route. In International Symposium on Certification of GNSS Systems \& Services (pp. 28-29).

[79] Bortolotto, M., Choquette, F. (2003). EGNOS trials on Italian highspeed tilting trains. In proceedings of the GNSS 2003 conference, Graz, Austria.

[80] Ali, K., Pini, M., \& Dovis, F. (2012). Measured performance of the application of EGNOS in the road traffic sector. GPS solutions, 16(2), 135-145.

[81] Filip, A., Bazant, L., \& Mocek, H. (2010, July). The experimental evaluation of the EGNOS safety-of-life services for railway signalling. In 12th International Conference on Computer System Design and Operation in Railways and Other Transit Systems.

[82] Salvatori, P., Neri, A., Stallo, C., Palma, V., Coluccia, A., \& Rispoli, F. (2014, September). Augmentation and Integrity Monitoring Network and EGNOS performance comparison for train positioning. In Proceedings of the 22nd European Signal Processing Conference (EUSIPCO), 2014 (pp. 186-190).

[83] Rispoli, F., Filip, A., Castorina, M., Di Mambro, G., Neri, A., \& Senesi, F. (2013, April). Recent progress in application of GNSS and advanced communications for railway signaling. In Radioelektronika (RADIOELEKTRONIKA), 2013 23rd International Conference (pp. 1322).

[84] Neri, A., Filip, A., Rispoli, F., \& Vegni, A. M. (2012). An analytical evaluation for hazardous failure rate in a satellite-based train positioning system with reference to the ERTMS train control systems. In Proceedings of the 25th International Technical Meeting of the Satellite Division of the Institute of Navigation (ION GNSS 2012). The Institute of Navigation

[85] Rhinos project; started in 2016. http://www.rhinos-h2020.org/

[86] Arrizabalaga, S., Mendizabal, J., Pinte, S., Sanchez, J. M., Bauer, J., Themistokleous, M., \& Lowe, D. (2014, April). Development of an Advanced Testing System and Smart Train Positioning System for 
ETCS applications. In Transport Research Arena (TRA) 5th Conference: Transport Solutions from Research to Deployment.

[87] Barbu, G., \& Marais, J. (2014, January). The SATLOC project. In TRATransport Research Arena (p. 10p).

[88] Senesi, F. (2013). Satellite application for train control systems: The Test Site in Sardinia. Journal of Rail Transport Planning \& Management, 2(4), 73-78.

[89] Stolagiewicz, A. A. (2009). Contributions to the foundations of a safety case for the use of GNSS in railway environments (Doctoral dissertation, UCL (University College London)).

[90] Vegni, C., Tosti, M., \& Vegni, A. M. (2013). Innovative radiating systems for train localization in interference conditions. International Journal of Antennas and Propagation, 2013.

[91] RSSB Research Brief, Obtaining data to assess the dependability of GNSS information and accuracy of odometry, T510 - December 2009.

[92] Lu, D., Wang, J., Cai, B. (2015). GNSS Signal Characteristic Analysis in Railway Application Environment In proceedings of CERGAL, Darmstadt, Germany.

[93] Kubo, N., Higuchi, M., Takasu, T., \& Yamamoto, H. (2015, October). Performance evaluation of GNSS-based railway applications. In Navigation World Congress (IAIN), 2015 International Association of Institutes of (pp. 1-8). IEEE.

[94] Poliak, J., Marais, J., Hänsel, F., Becker, U., Schnieder, E. (2008). Methods and Tools for the Certification of GALILEO for Railway Applications. In the proceedings of the 8th World Congress of Railway Research, May, Seoul.

[95] Marais, J., Meurie, C., Flancquart, A., Lithgow, S., Barbu, G. (2014, January). Innovative simulations of GNSS performances in a realistic railway environment. In CERGAL, International Symposium on Certification of GNSS Systems \& Services (5p).

[96] Manz, H., \& Schnieder, E. (2013, August). Implementation of the normative safety case structure for satellite based railway applications. In Intelligent Rail Transportation (ICIRT), 2013 IEEE International Conference on (pp. 203-208).

[97] EN 50126 (2000). Railway Applications - Specification and demonstration of Reliability, Availability, Maintainability and Safety (RAMS). CENELEC European standard (European Committee for Electrotechnical Standardization).

[98] EN 50128 (2011). Railway Applications - Communication, signalling and processing systems - Software for railway control and protection systems. CENELEC European standard (European Committee for Electrotechnical Standardization).

[99] EN 50129 (2003). Railway Applications - Communication, signalling and processing systems - Safety related electronic systems for signalling. CENELEC European standard (European Committee for Electrotechnical Standardization).

[100]Marzoni, M. G., Lippi, A., Rispoli, F., Senesi, F., Rapaccini, A. (2015). On the Certification Process for Satellite-based Applications in the ERTMS ETCS Train Control System, In Proceedings of European Navigation Conference 7-10 April, 2015, Bordeaux (France).

[101] Antón, V., (2013). GRAIL-2 project report D4.2, Safety Approval Process.

[102] Regulation 402/103/EU (2013) on the Common Safety Method for risk evaluation and assessment. European Commission. Amended by the Implementing Regulation (EU) 2015/1136.1.

[103] Benusiglio, S. (2013). Evaluation of Thales GNSS UT odometric system based on satellite signals. Report from Bureau Veritas for the GRAIL-2 project.

[104]Beugin, J., Marais, J., \& Lozac'h, J. P. (2008). A dependability analysis for integrating a satellite positioning system in a rail freight application. In European Navigation Conference.

[105] Nguyen, T. K., Beugin, J., \& Marais, J. (2015). Method for evaluating an extended Fault Tree to analyse the dependability of complex systems: Application to a satellite-based railway system. In Reliability Engineering \& System Safety, 133, 300-313.

[106] Nguyen T.P.K., Beugin J., Marais J. (2014). RAMS analysis of GNSS based localisation system for the train control application. IEEE ComManTel 2014, Conference on Computing, Management and Telecommunications, April 27-29, Da Nang, Vietnam.

[107]Legrand,C., Beugin, J., Conrard, B., Marais, J., Berbineau, M., ElKoursi,E.-M., Approach for evaluating the safety of a satellite-based train localization system through the extended integrity concept, In European Safety and Reliability Conference ESREL 2015, 7-10 sept. 2015, Zurich, Suisse.

[108]Legrand, C., Beugin, J., Marais, J., Conrard, B., El-Koursi, E. M., \& Berbineau, M. (2016). From extended integrity monitoring to the safety evaluation of satellite-based localisation system. Reliability Engineering \& System Safety.

[109]Wu, D., \& Schnieder, E. (2016). Scenario-Based Modeling of the OnBoard of a Satellite-Based Train Control System With Colored Petri Nets. In IEEE Transactions on Intelligent Transportation Systems. (accepted February 22, 2016)

[110]Liu, J., Cai, B. G., Wang, Y. P., Wang, J., \& Shangguan, W. (2012, September). A GPS/compass based train integrated positioning method for high-speed railways. In Antennas and Propagation in Wireless Communications (APWC), 2012 IEEE-APS Topical Conference on (pp. 1201-1204).

[111] Alcantarilla, I., Porras, D., Tajdine, A., Zarraoa, N., \& Lévy, J. C. (2006, September). The benefits of multi-constellation GNSS augmentations. In Proceedings of the 19th International Technical Meeting of the Satellite Division of The Institute of Navigation (ION GNSS 2006), Fort Worth, TX (pp. 930-938).

[112]Li, X., Zhang, X., Ren, X., Fritsche, M., Wickert, J., \& Schuh, H. (2015). Precise positioning with current multi-constellation global navigation satellite systems: GPS, GLONASS, Galileo and BeiDou. Scientific reports, 5.

\section{GLOSSARY}

AIMA

AIMN

AL

ANSF

APOLO

ATLAS

ATMS

ARTC

ATC

ATP

CBTC

CCS TSI

CPN

EATS

ECS

EGNOS

ERA

ERSAT (EAV)

ERTMS

ETCS

EVC

eFT

FDD/FDE

GADEROS

GALOROI

GBAS

GIRASOLE

GIVE

GLONASS

GNSS

GPS

GRAIL

GRAIL-2

GSM-R

HDOP

ICAO

ISA

LDS

LOCOPROL

LOS/NLOS

MOPS

NGTC

NSA

NoBo
Autonomous Integrity Monitoring and Assurance Augmentation and Integrity Monitoring Network Alert Limit

Agenzia Nazionale per la Sicurezza delle Ferrovie Advanced Position Locator

Advanced Train LocAtion Simulator

Automated Train Management System

Australian Rail Track Corporation

Automatic Train Control

Automatic Train Protection

Communication-Based Train Control

Technical Specification for Interoperability relating to the Control-Command and Signaling

Colored Petri Net

ETCS Advanced Testing and Smart Train Positioning System

Eddy Current Sensor

European Geostationary Navigation Overlay Service

European Railway Agency

ERTMS on SATELLITE (Enabling Application Validation)

European Rail Traffic Management System

European Train Control System

European Vital Computer

extended Fault Tree

Fault Detection and Diagnosis/Exclusion

Galileo Demonstrator for Railway Operation System

Galileo Localization for Railway Operation Innovation

Ground-Based Augmentation System

Galileo Receiver for Safety of Life Equipment

Grid Ionospheric Vertical Error

GLObalnaïa NAvigatsionnaïa Spoutnikovaïa Sistéma

Global Navigation Satellite Systems

Global Positioning System

GNSS introduction in the RAIL Sector

GNSS-based enhanced odometry for Rail

GSM for railway

Horizontal Dilution of Precision

International Civil Aviation Organization

Independent Safety Assessor

Location Determination System

Low Cost satellite based train location system for signalling and train Protection for Low-density traffic railway line

Line-of-Sight/Non-line-of-Sight

Minimum Operational Performance Standard

Next Generation Train Control

National Safety Authority

Notified bodies 


$\begin{array}{ll}\text { PL/HPL } & \text { Protection Level/Horizontal PL } \\ \text { PA/NPA } & \text { Precision Approach/Non Precision Approach } \\ \text { PVT } & \text { Position, Velocity and Time } \\ \text { RAIM } & \text { Receiver Autonomous Integrity Monitoring } \\ \text { RBC } & \text { Radio Block Center } \\ \text { RAMS } & \text { Reliability, Availability, Maintainability and Safety } \\ \text { RHINOS } & \text { Railway High Integrity Navigation Overlay System } \\ \text { RIMS } & \text { Ranging Integrity Monitoring Stations } \\ \text { RIM RS } & \text { Ranging \& Integrity Monitoring Reference Stations } \\ \text { RNP } & \text { Required Navigation Performances } \\ \text { RSSB } & \text { Rail Safety and Standards Board } \\ \text { RUNE } & \text { Railway User Navigation Equipment } \\ \text { SaPPART } & \text { Satellite Positioning Performance Assessment for Road } \\ & \text { Transport } \\ \text { SIL } & \text { Safety Integrity Level } \\ \text { SBAS } & \text { Satellite-Based Augmentation System } \\ \text { STARS } & \text { Satellite Technology for Advanced Railway Signalling } \\ \text { TDOA } & \text { Time Difference of Arrival } \\ \text { THR } & \text { Tolerable Hazard Rates } \\ \text { TTA } & \text { Time To Alert } \\ \text { TOA } & \text { Time of Arrival } \\ \text { UDRE } & \text { User Differential Range Error } \\ \text { UNISIG } & \text { Union industry of signalling } \\ \text { WCT } & \text { Wireless Communications Technology } \\ \text { QZSS } & \text { Quasi Zenith Satellite Solution } \\ \text { 3inSat } & \text { Train Integrated Safety Satellite System } \\ & \end{array}$

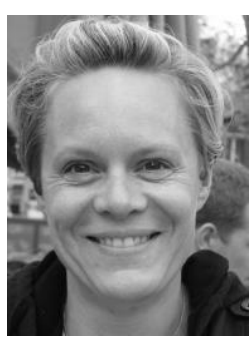

Juliette Marais received the engineering degree from the Institut Supérieur de l'Electronique et du Numérique (ISEN) and Ph.D. degree in electronics from University of Lille, France, in 1998 and 2002 respectively. Since 2002, she is a researcher with IFSTTAR, the French institute of science and technology for transport, development and networks. She is working on GNSS performance analyses and enhancement in land transport environments. She is participating in European railway-related projects since the 2000's (Locoprol, Satloc, GaloRoi, STARS). She is currently involved on two main research projects: integrity monitoring for land transport applications and GNSS propagation characterization in railway environments. Her research interests principally include propagation phenomena, positioning and pseudorange error modelling, filtering technics, and simulation. She is author and co-author of 80 articles and one patent.

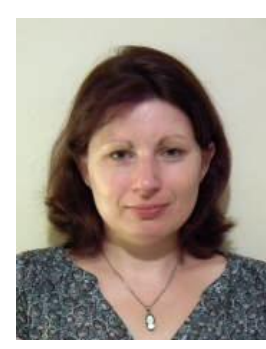

Julie Beugin. Doctor in Automation Engineering, she received an Engineering degree from the ENSIAME (the National School of Engineering for Computer Science, Automation, Mechanics and Electronics) in 2002. She received a Master degree in Automation Engineering from the University of Valenciennes (France) in 2002 and a $\mathrm{PhD}$ in Automation Engineering in December 2006. Her PhD dealt with the safety assessment of railway safety-related systems using risk concepts and RAMS evaluation methods (Reliability, Availability, Maintainability and Safety). Since 2007, she is working within IFSTTAR as a researcher. Her research interest deals with dependability and safety evaluation of complex guided transportation systems. Part of her activities addresses RAMS demonstration issues of GNSSbased solutions embedded in train control applications. She participated to the GaLoROI European project and is now involved in the STARS project. Her recent activities address, in addition, dependability analysis of the LTE-based wireless communication links used in CBTC applications.

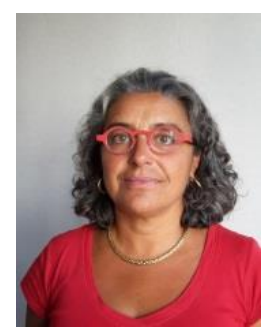

Marion Berbineau received the Engineer degree from Polytech'Lille (France) and the Ph.D. degree from the Univ. of Lille, both in electrical engineering, respectively in 1986 and 1989. She is a full time Research Director at IFSTTAR. She is expert in the field of radio wave propagation in transport environments (tunnels), electromagnetic modeling, channel characterization and modeling, MIMO, wireless systems for telecommunications, cognitive radio for railways and GNSS localization-based for ITS particularly for the rail and public transport domains. She is active as an expert for the GSM-R and future systems like LTE-A or 5G. She is involved in several National and European research projects. She is author and co-author of several publications and patents. 